\title{
Bacterias, fuente de energía para el futuro
}

\section{Bacteria, source of energy for the future}

\begin{abstract}
Alba Ayde Romero Mejía
Tecnóloga en Electricidad. Tecnóloga en Distribución Eléctrica de Codensa. Bogotá, Colombia.mejia214@gmail.com

Jorge Adrian Vásquez

Tecnóloga en Electricidad. Tecnólogo Operativo de la Universidad Militar Nueva Granada. Bogotá, Colombia.vasquez214@gmail.com

\section{Armando Lugo González}

Licenciado en Ciencias Sociales, especialista en Lenguaje y Pedagogía de Proyectos, magister en Investigación Social Interdisciplinar. Docente de la Universidad Distrital Francisco José de Caldas. Bogotá, Colombia. alugog@udistrital. edu.co
\end{abstract}

Clasificación del artículo: Revisión (Recreaciones)

Fecha de recepción: Agosto 26 de 2011

Fecha de aceptación: Febrero 27 de 2012

Palabras clave: celda de combustible microbiana, electricidad, Geobacter, impacto ambiental, materia orgánica.

Keywords: microbial fuel cell, electricity, geobacter, environmental impact, organic matter.

\section{RESUMEN}

El presente trabajo expone una familia de bacterias denominadas Geobacter que tienen la capacidad de producir energía eléctrica como fuente renovable en una celda de combustible microbiana. Estas bacterias pueden oxidar totalmente com- puestos orgánicos, empleando diferentes elementos o sustancias como aceptores de electrones.

El trabajo aborda características principales de la bacteria, como los mecanismos utilizados para aprovechar la electricidad que genera y una aproximación sobre el sistema requerido para 
convertirla en una fuente de energía renovable competitiva. Los resultados muestran un análisis comparativo de fuentes de energía convencionales y no convencionales con respecto a la familia de bacterias Geobacter.

\section{ABSTRACT}

This paper presents a family of bacteria called Geobacter that have the ability to produce power as a renewable source in a microbial fuel cell.
These bacteria can completely oxidize organic compounds using different elements or substances as electron acceptors.

The paper addresses key features of the bacteria, the mechanisms used to harness the electricity generated and an approximation of the system required to become a competitive source of renewable energy. The results show a comparative analysis of sources of conventional and unconventional energy with respect to the Geobacter family of bacteria.

\section{INTRODUCCIÓN}

Este texto es producto del desarrollo de la investigación titulada "La calidad de la educación superior en Colombia en el nuevo orden mundial", aprobada por el CIDC (Centro de Investigación y Desarrollo Científico) de la Universidad Distrital, el cual se enmarca dentro de los proyectos desarrollados por el grupo de investigación GIDETCI (Grupo de Investigación en Educación Tecnológica por Ciclos), clasificado por COLCIENCIAS.

Es de aclarar que aunque la temática aparentemente no tiene que ver con la calidad de la educación superior en Colombia, el tema toma total relevancia cuando se afrontan los retos de la universidad, entre ellos la investigación, específicamente la exigencia mundial por la búsqueda de nuevas fuentes de energía.

En la actualidad se utiliza combustible fósil -carbón, petróleo y gas- para generar energía eléctrica, lo que altera lenta pero irremediablemente nuestro clima, emitiendo grandes cantidades de dióxido de carbono que retienen el calor del sol que llega a la Tierra, produciendo lo que se conoce como efecto invernadero. Un aumento en uno o dos grados Celsius en la temperatura media mundial puede ser catastrófico y tener consecuen- cias como: deshielo en los polos geográficos y los glaciares, aumento desmesurado en los niveles pluviométricos en algunas zonas del planeta, sequía en otras, inundaciones costeras, desbordamientos de ríos, aumento en el nivel del mar, cambios irreversibles en los ecosistemas, pérdida de cosechas, hambrunas, entre otras. Por otra parte, se puede producir degradación de los recursos naturales en tierras áridas que crean condiciones desérticas, vientos más fuertes, tormentas, huracanes, derrumbes, caídas y flujo de materiales no consolidados, etc.

La forma en que se utilizan los combustibles destruye el paisaje, ocasiona vertidos de petróleo, produce polución en nuestras aguas, causa lluvia ácida y contaminación urbana; lo que acaba con los bosques, asfixia las ciudades y acorta la vida humana. Sin dejar de lado que en los procesos de explotación y producción energética utilizado hasta el día de hoy, impactan significativamente el medio ambiente. Ante tal problema, es imprescindible obtener nuevas fuentes de energía eléctrica que causen un mínimo impacto en el medio ambiente y no dependan de los combustibles fósiles.

El término "bacteria" es asociado con infecciones, enfermedades y descomposición. Sin embargo, por la respiración interna, un fundamento de la 
actividad metabólica, hay microorganismos de la especie Geobacter que el ser humano ha empleado como aliado en la investigación de múltiples aplicaciones favorables. El género de bacterias denominada Geobacter de la familia Geobacteraceae de la cual sobresalen dos especies, el metallireducens y el sulfurreducens [1], poseen características sobresalientes que bien administradas, pueden contribuir en múltiples trabajos a la humanidad.

La bacteria del género Geobacter tiene la capacidad de transferir electrones a moléculas como el Fe (III) y Mn (IV) [2], óxidos de nitrógeno [3], sustancias de alto peso molecular formadas por la degradación química y biológica de restos de plantas y de animales [4]. Además permite la transferencia de electrones de forma directa a los electrodos, generando pequeñas corrientes eléctricas [5], esta característica le permite a la especie Geobacter jugar un papel importante en el ciclo natural de la materia orgánica y de los metales en los sedimentos acuáticos y subsuelos [6], en la biorremediación de compuestos orgánicos y en el metal contaminante presente en ambientes subterráneos [7].

La capacidad de las especies Geobacter para transferir electrones desde y hacia electrodos permite obtener electricidad a partir de materia orgánica [8], o el uso de electrodos como donador de electrones para la reducción de contaminantes tales como; nitrato, uranio y disolventes clorados [9] - [11]. Además estas bacterias son capaces de fabricar Pili, que pueden ser útiles en el desarrollo de dispositivos en la industria de microelectrónica [12].

\section{CARACTERÍSTICAS}

\subsection{Origen y evolución}

El Geobacter fue descubierto en 1987 en el sedimento de agua dulce del río Potomac en Washing- ton D.C, por el doctor Derek Lovley y un equipo de investigadores de la Universidad de Massachusetts Amherst [13]. A las primeras bacterias se les asignó el nombre de Geobacter metallireducens (GS 15) [1].

Originalmente el Geobacter fue asociado con la capacidad de producir magnetita (imán natural) en los ambientes sedimentarios terrestres, prosiguió el descubrimiento con: la facultad de respirar uranio nocivo para el medio ambiente y convertirlo en un elemento neutro; la biodegradación anaerobia de compuestos aromáticos derivados del petróleo; la respiración de ácidos húmicos en ambientes naturales; la capacidad de generar electricidad empleando materia orgánica y la identificación de nanocables conductores "Pili" [2].

Desde el hallazgo hasta nuestros días, Derek Lovley y sus colegas han encontrado más de 20 especies de la familia Geobacter, precisando nuevas habilidades, como la capacidad de moverse hacia sustancias metálicas y los indicios de actividad metabólica aeróbica, lo que indica que el Geobacter puede sobrevivir a la exposición de oxígeno [13], [14].

\subsection{Descripción general}

El género de bacterias "Geobacter" se encuentra clasificado en el grupo Deltaproteobacteria de la familia Geobacteracea, son Gram-negativas, se caracteriza en general por tener una forma recta o ligeramente curvada, su tamaño puede variar de 1,2-2,0 $\mu \mathrm{m}$ de longitud por 0,5-0,6 $\mu \mathrm{m}$ de diámetro, además, se caracteriza en general por poseer dos tipos de apéndices celulares, flagelos y Pili [15] - [17] (Fig. 1).

Los Flagelos son estructuras proteicas, cuya función es permitir el desplazamiento de la bacteria por deslizamiento en su hábitat, evitando condiciones nocivas. Estas estructuras están ubicadas en la parte externa de la célula, pueden ser una o 


\section{re-creaciones}

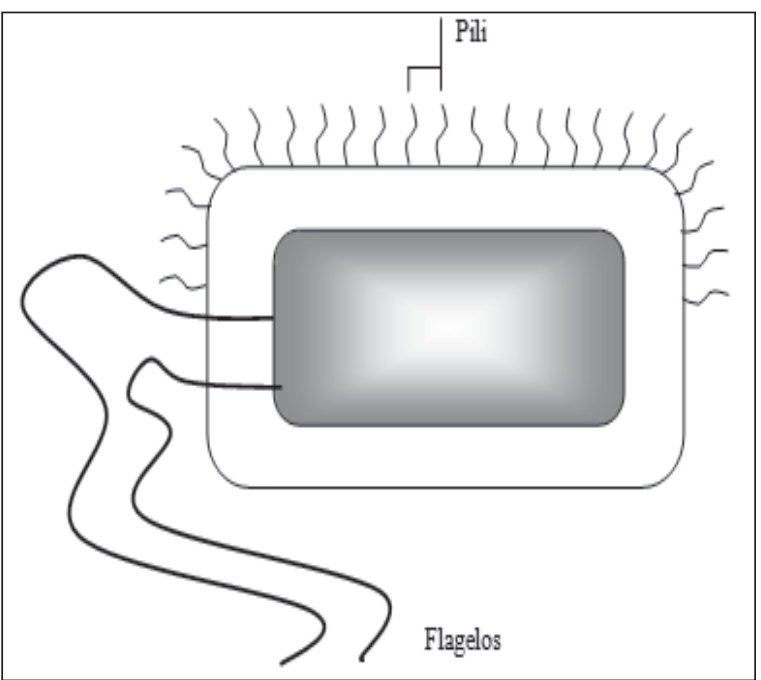

Fig. 1. Estructura externa y Pili de una célula del genero Geobacter.

Tomada de: http://blogs.nature.com/from the_lab_bench/2011/06/13/computers-andelectrifying-bacteria

dos por célula, el tamaño es aproximadamente de $20 \mathrm{~nm}$ de diámetro por una longitud de hasta 16 $\mu \mathrm{m}$. La presencia del flagelo es imprescindible en la búsqueda de Fe (III) y metales, así como para desplazarse de una partícula solida a otra, una vez se agota el óxido respirable.

Los Pili son estructuras eléctricamente conductoras de proteínas, cuya función es transferir electrones desde la superficie externa del Geobacter hasta aquellos materiales que se logran reducir, estas estructuras se encuentran localizadas a un costado de la célula, su número puede variar entre 100 y hasta 1000 por bacteria, su tamaño es aproximadamente de 3-5 nm de diámetro por 1-5 $\mu \mathrm{m}$ de longitud. Estas estructuras son de gran importancia ya que permiten al Geobacter llevar a cabo la habilidad de transferir electrones al hierro insoluble, metales o electrodos. La afirmación anterior se demostró en una experiencia [16], [18 ] - [20] con la utilización de un microscopio atómico, donde se encontró que los Pili eran altamente conductores.

\subsection{Hábitat}

El Geobacter se puede encontrar en sedimentos de agua dulce, sedimentos marinos anóxicos, sedimentos de sal de pantano, ambientes subterráneos y acuíferos. Estos ambientes se caracterizan principalmente por ser ricos en nitratos y sulfatos, pero al mismo tiempo deben ser espacios libres de oxígeno puro [21].

\subsection{Metabolismo}

En general el metabolismo celular de los microorganismos para degradar los contaminantes, depende de la forma de obtención de energía de estos, de esta forma se clasifican: los que utilizan luz, se denominan fotótrofos; los que utilizan compuestos orgánicos, se denominan quimioorganótrofos; y los que son capaces de utilizar compuestos inorgánicos, se denominan quimiolitótrofos. En particular el metabolismo celular de la especie Geobacter es quimioorganótrofo anaerobio, es decir, utilizan compuestos orgánicos como fuente de energía y de carbono para su crecimiento y desarrollo.

En los procesos redox de respiración anaerobia es necesario la presencia de posibles receptores de electrones como son: nitratos, sulfatos, fumarato, ferricianuro, fe (III) [2] - [4], [9], [4], [22], [23], oxígeno [24] y electrodos [8], [10], [18], [25].

El Geobacter posee una red de citocromos tipo C multihemo [1], [14], [15], [20], [24], [25], una proteína que funciona como mecanismo de transporte electrónico y vincula entre sí la membrana interna, el periplasma y la membrana externa, (Fig. 2), con el fin de transferir los electrones desde una sustancia que es oxidada a otra que se reduce o acepta electrones, por ejemplo: la bacteria adquiere electrones de la materia orgánica y los cede a un ión férrico $\mathrm{Fe}^{3+}$ (forma insoluble) que se reduce en un ión ferroso $\mathrm{Fe}^{2+}$ (forma soluble). Para obtener los electrones el Geobacter 


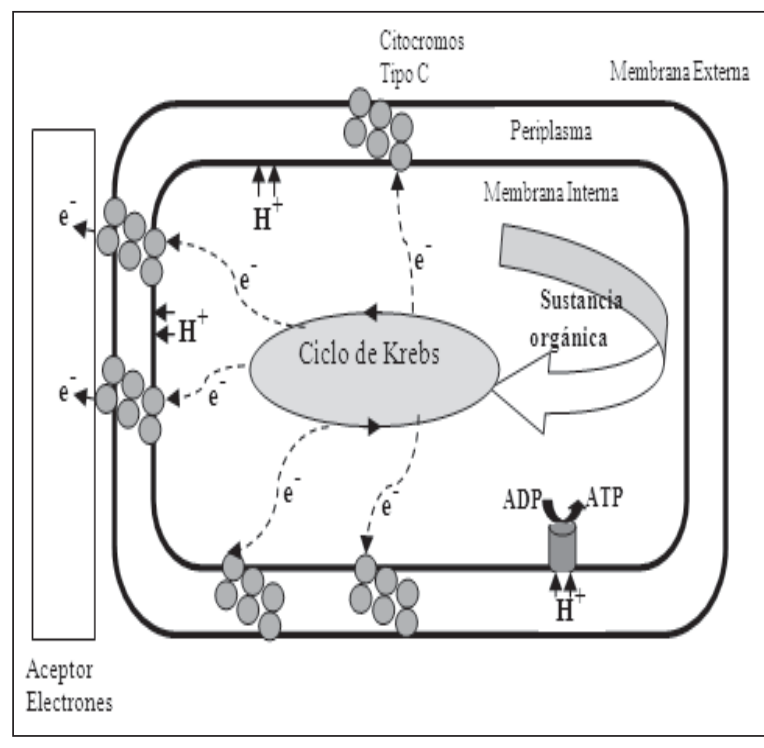

Fig. 2. Modelo metabólico de una célula del genero Geobacter.

Tomada de: http://www.geobacter.org/publication-files/16778836.pdf

utiliza la respiración e internamente aplica el ciclo Krebs, una sucesión de reacciones químicas que oxidan completamente la materia orgánica hasta producir dióxido de carbono, agua, energía en forma utilizable (electrones) y ATP [3]. Además, la red de Citocromos Tipo $\mathrm{C}$ actúa como un capacitor almacenando energía para mantener la célula activa en su búsqueda de nuevos aceptores de electrones [26], [27].

\subsection{Crecimiento y reproducción}

El crecimiento y reproducción del género Geobacter ocurre a medida que los nutrientes son procesados e incorporados como nuevo material de célula. El proceso reproductivo de esta bacteria es fisión binaria, donde las células individuales se duplican a una tasa característica. El tiempo que requiere una célula de Geobacter en duplicarse es aproximadamente $19 \pm 3.6 \mathrm{~h}$ en laboratorio [18]. El crecimiento de esta población se compone de una serie de fases. En la primera etapa (fase lag) las células se ajustan a su nuevo ambiente. En la segunda etapa se entra a la fase exponencial, en la cual la población se duplica a intervalos regulares, este es el período de más rápido crecimiento bajo condiciones óptimas de $\mathrm{pH}$ y temperatura. Cuando el número de células que son producidas es igual al número de células que mueren, se establece un equilibrio dinámico en el cual el crecimiento bacteriano se detiene, esta etapa se denomina fase estacionaria y se debe a un agotamiento de algún nutriente. La fase de muerte o declinación se alcanza cuando la tasa de destrucción supera la tasa de crecimiento (Fig. 3).

Se encontró que el crecimiento óptimo de esta especie se produce cuando el $\mathrm{pH}$ se encuentra en el rango de 6,2-7,4 y la temperatura en el rango de $22-30^{\circ} \mathrm{C}$; no se observa crecimiento cuando el $\mathrm{pH}$ es inferior a 5,8 o superior a 8,0 y la temperatura es inferior a $10{ }^{\circ} \mathrm{C}$ o superior a $36^{\circ} \mathrm{C}$ en los siguientes estudios realizados [15] - [17], [19] con cepas del género Geobacter bajo condiciones adecuadas y nutrientes básicos (Tabla 1).

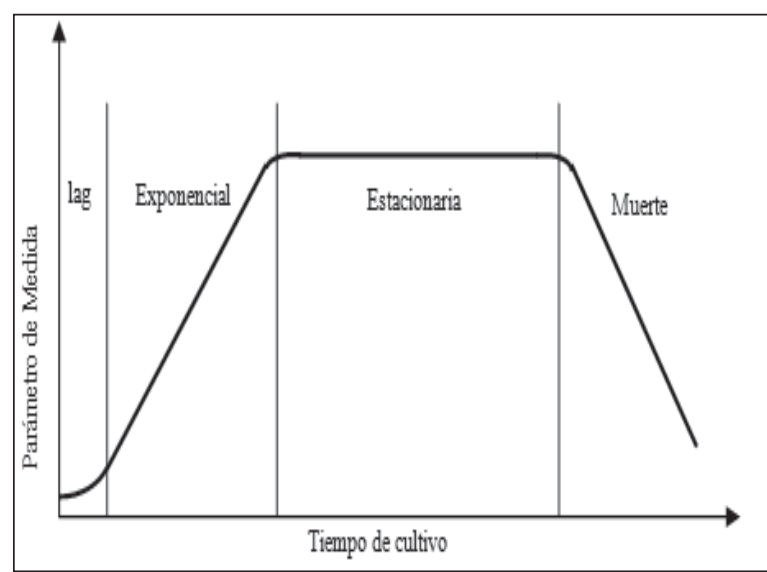

Fig. 3. Fases de crecimiento de una biopelícula de Geobacter.

Tomada de: http://aulavirtual.usal.es/aulavirtual/demos/microbiologia/unidades/documen/uni_02/58/texthtml/cap802.htm 
Tabla 1. Resultados de las características y condiciones de ambiente para el desarrollo y crecimiento del Geobacter [15] - [17], [19].

\begin{tabular}{|c|c|}
\hline HÁBITAT & $\begin{array}{c}\text { Sedimentos de agua dulce, de sal } \\
\text { de pantano y marinos Ambientes } \\
\text { subterráneos Acuíferos }\end{array}$ \\
\hline ENTORNO & $\begin{array}{c}\text { Ricos en nitratos Ricos en sustratos } \\
\text { Carentes de oxigeno }\end{array}$ \\
\hline TEMPERATURA & $22-30$ ○C \\
\hline $\begin{array}{c}\text { POTENCIAL } \\
\text { DE HIDRÓGENO } \\
(\mathrm{pH})\end{array}$ & $6,2-7,4$ \\
\hline
\end{tabular}

Con el fin de determinar una ecuación como modelo matemático que describa el crecimiento del Geobacter se debe tener en cuenta un estudio [18] donde la bacteria se duplico en $19 \mathrm{~h}$. Por tanto si previamente se tenía un cultivo $P_{0}$ de bacterias. En $\mathrm{t}=19 \mathrm{~h}$ se determina que el número de bacterias es de $2 P_{0}$. Entonces la ecuación diferencial que sirve como modelo es $d P / d t=k P$ donde $k$ es la constante de proporcionalidad. Si $t_{0}=0$ entonces $P(0)=P_{0}$ y $P(19)=2 P_{0}$ están condiciones son necesarias para determinar $k$. Se adecua la ecuación diferencial en una forma estándar de primer orden, como la Ec. (1).

$$
\frac{d P}{d t}-k P=0
$$

El factor integrante es $e^{k t}$. Se multiplica ambos lados de la ecuación y al integrar se obtiene la Ec. (2).

$$
\begin{gathered}
\frac{d}{d t}\left[e^{-k t} P\right]=0 \quad y \quad e^{-k t} P=c \\
P(t)=c e^{k t}
\end{gathered}
$$

Por tanto, si se reemplazan las condiciones iniciales se obtiene la ecuación de crecimiento de un ultivo de bacterias en función del tiempo con condiciones y nutrientes óptimos, ver ecuación Ec. (3).

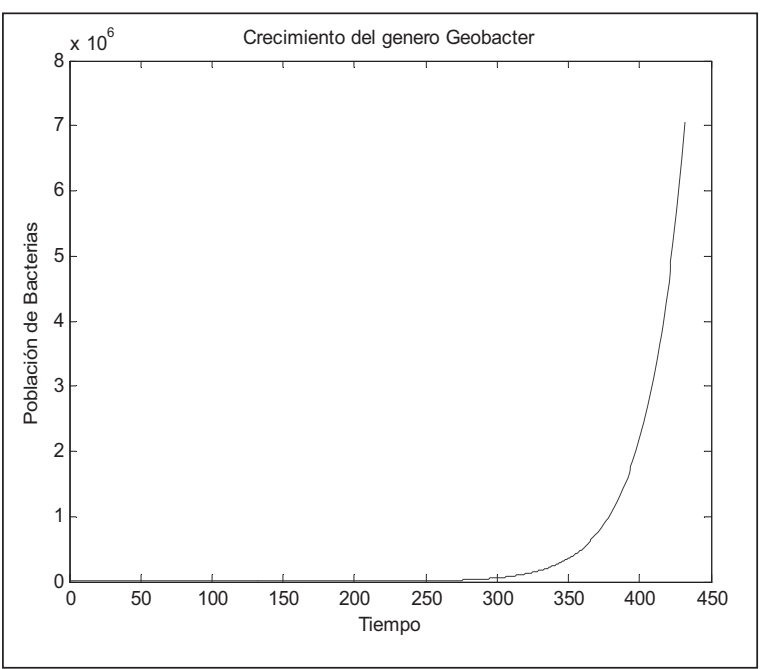

Fig. 4. Crecimiento de la población del Geobacter, fase exponencial.

$$
P(t)=P_{0} e^{0.0365 \times t}
$$

Si se toma $P_{0}=1$ y como el tiempo de crecimiento fue igual a 18 días equivalente 432 horas, entonces la Fig. 4 Representa el crecimiento de la población de bacterias en función del tiempo.

De acuerdo con este comportamiento, la población de este género de bacterias en solo 18 días alcanzaría a multiplicarse hasta por $7 \times 10^{6}$ veces.

De acuerdo con las características expuestas en la Tabla 1 se deducen aquellos departamentos y zonas en Colombia viables para hallar las bacterias del género Geobacter.

El hábitat de estas bacterias generalmente son los sedimentos procedentes de las rocas o suelos que son transportadas por las aguas de los escurrimientos y por el viento. Por tanto la principal fuente de los sedimentos la constituyen los suelos y las rocas que se encuentran en la cuenca de los ríos, donde el agua y el viento son los agentes de erosión y transporte. Las rocas que componen estos medios son normalmente 


\section{|re-creaciones}

sedimentarias que participan activamente en fluidos acuosos superficiales, los océanos, los ríos, etc.

Se analizó el atlas geológico de Colombia; un documento de referencia científica y pedagógica donde se muestra sobre un mapa la distribución de las rocas y materiales superficiales no consolidados y las estructuras que los afectan, así como los estudios hidrogeológicos de Córdoba y Sucre [28], [29] que incluyen características físico-químicas de los acuíferos con valores de $\mathrm{pH}$, temperatura, entorno y hábitat similares a los de referencia. Por tanto se determinan los sedimentos constituidos por depósitos no conso-

Tabla 2. Zonas seleccionadas por regiones en Colombia que cumplen condiciones para hallar el Geobacter

\begin{tabular}{|c|c|}
\hline Departamento & Zonas \\
\hline GUAJIRA & $\begin{array}{c}\text { Punta de: Tarolta, Huayapain, Taroa, } \\
\text { Gallinas y Coco } \\
\text { Arroyos de: Topio, Mashurahu, } \\
\text { Patsua y Orocho }\end{array}$ \\
\hline $\begin{array}{l}\text { MAGDALENA, } \\
\text { ATLÁNTICO, } \\
\text { CESAR, BOLÍVAR }\end{array}$ & $\begin{array}{l}\text { Rio Tapias en intercepción } \\
\text { con Falla de la Oca } \\
\text { Hato Nuevo. Punta de: Sabanilla, } \\
\text { Manzanillo Puerto Colombia }\end{array}$ \\
\hline $\begin{array}{l}\text { BOLÍVAR, SUCRE, } \\
\text { CÓRDOBA, AN- } \\
\text { TIOQUIA CHOCÓ } \\
\text { Y NORTE } \\
\text { DE SANTANDER }\end{array}$ & $\begin{array}{c}\text { Falla de: San Sebastián, Canalette, } \\
\text { Turbaná, La bonga Punta de Piedra. } \\
\text { Anticlinal del Guamo. Arrollo el } \\
\text { Burrito Sinclinal de Doguado. Rio } \\
\text { Pichicora y Pogué }\end{array}$ \\
\hline ARAUCA & $\begin{array}{c}\text { Sinclinal de las Mercedes Falla de: } \\
\text { Mesón, Aguablanca, Sacama y } \\
\text { Samaria }\end{array}$ \\
\hline $\begin{array}{l}\text { CALDAS, } \\
\text { RISARALDA, } \\
\text { TOLIMA, VALLE } \\
\text { Y QUINDÍO }\end{array}$ & $\begin{array}{c}\text { Falla de: Quebrada Santa Barbará, } \\
\text { Rio Pepe, Rio Condotico Rio Nauca, } \\
\text { Rio Certegui y Rio Orpua El Litoral } \\
\text { del San Juan. } \\
\text { Santa Genoveva de Docordó }\end{array}$ \\
\hline
\end{tabular}

Tomada de: http://www.ingeominas.gov.co/Geologia/Mapa-geologico-de-Colombia/Atlas-Geologico-de-Colombia. aspx lidados de ambiente lacustre, deltaico y marino y por rocas sedimentarias terciarias a cretácicas poco consolidadas a muy consolidadas, de origen marino y continental, las cuales conforman acuíferos de muy baja productividad. Con estos datos se especifican las regiones por su litología que son viables para hallar la familia de bacteria del género Geobacter. En la Tabla 2 se relacionan los departamentos y aquellas zonas que cumplen las características y condiciones medio ambientales de las bacterias.

\section{PROCEDIMIENTO APLICADO POR EL GEOBACTER PARA PRODUCIR ENERGÍA ELÉCTRICA}

El Geobacter es capaz de transformar internamente energía química en energía eléctrica, transfiriendo los electrones derivados de la oxidación de compuestos orgánicos (acetato) a electrodos y así constituir una celda de combustible microbiana (Microbial Fuel Cell, MFC) [30].

\subsection{Reseña histórica de las celdas de combustible microbianas}

El primer relato científico sobre organismos vivos y su relación con la electricidad se atribuye a Luigi Galvani, en 1791, mientras disecaba una rana halló accidentalmente que sus patas se contraían al tocarlas con un objeto cargado con corriente eléctrica [31], [32].

En 1910, Michael Cresse Potter, investigador de la Universidad de Durham, observó energía libre cuando la bacteria Escherichia coli actuaba sobre el sustrato orgánico [24], [32] - [34].

En 1931, Barnett Cohen, un investigador de Cambridge, describe un grupo de celdas de combustible biológico capaz de producir un voltaje de 35 VDC y una corriente de $2 \mathrm{~mA} \mathrm{[32],} \mathrm{[35].}$ 
En 1960, las celdas de combustible microbiana alcanzan su popularidad cuando la Administración Nacional de Aeronáutica y del Espacio en Estados Unidos de América (NASA) manifestó su interés. El objetivo era convertir residuos orgánicos producto de los vuelos al espacio en energía eléctrica. Los organismos empleados eran algas y bacterias [32], [35], [36].

En 1962 Rohrback G. diseñó una celda de combustible microbiana donde utilizó Clostridium butyricum como catalizador para generar hidrógeno mediante fermentación de glucosa [32].

En 1963 algunas celdas de combustible biológicas se comercializaron en el mercado como fuente de energía para: receptores de radio, luces de señalización y diversos aparatos en alta mar. Sin lograr el éxito comercial deseado y pronto desapareció del mercado [32].

En 1966 Williams K. presentó un conjunto de celdas de combustible microbianas alimentadas con cáscara de arroz y conectadas en serie, con la capacidad de producir aproximadamente un voltaje de 6V y una corriente eléctrica de 40 mADC [32].

En 1969 Yao S. encontró que la glucosa se puede utilizar como combustible para generar energía eléctrica en presencia de platinum-black y Karube I. reportó una corriente eléctrica de $300 \mathrm{~mA}$ de una celda de combustible biológica basada en Anabaena spp [32].

En la década de 1980 Allen M. J. y Peter H. Bennetto desarrollaron celdas de combustible microbianas, con una serie de microorganismos y sistemas mediadores que actúan como intermediarios entre las bacterias y los aceptores de electrones para que la transferencia de electrones y producción de energía sea eficiente [32], [33].

Actualmente, Chaudhuri S. K. y Derek R. Lovley han dado a conocer el microorganismo reductor de hierro conocido como Geobacter, capaz de re- cuperar hasta un $83 \%$ los electrones que se liberan durante la oxidación de la glucosa en la presencia de ión férrico $\left(\mathrm{Fe}^{3+}\right)$ [2], [24], [32], [33].

\subsection{Celda de combustible microbiana (Microbial Fuel Cell, MFC)}

Una MFC es un reactor bio-electroquímico capaz de convertir la energía química en energía eléctrica a través de reacciones químicas catalizadas por el Geobacter en condiciones anóxicas, ausencia de oxígeno puro $\mathrm{O}_{2}$, pero con presencia de sustancias tales como nitratos o sulfatos como agentes de oxidación cuando se descompone la materia orgánica. La MFC consiste básicamente en dos compartimentos, anódico y catódico, que están separados por una membrana permeable de intercambio de protones. El compartimiento anódico se debe conservar en condiciones anaeróbicas donde una biopelícula del Geobacter sobrepuesto en el ánodo oxida la materia orgánica y genera dióxido de carbono, protones y electrones. Los electrones viajan a través de una resistencia que conecta el ánodo y el cátodo originando una pequeña corriente que puede ser medida y utilizada para realizar trabajo. Los protones son transferidos por medio de la membrana permeable al compartimiento catódico que se encuentra normalmente en condiciones aeróbicas, en esta cámara se combinan los protones, los electrones y el oxígeno con el fin de generar agua [34] [36]-[39] (Fig. 5).

La transferencia de electrones sobre el electrodo es directa, no necesita de un agente oxidante gracias a los Pili que se adhieren a los electrodos y permiten que los electrones se transfieran desde la materia orgánica hasta el ánodo directamente [24], [25], [40].

Ánodo: los materiales con los que se deben construir los ánodos deben ser conductivos, biocompatibles y químicamente estables en la solución del reactor. El material del electrodo más versá- 


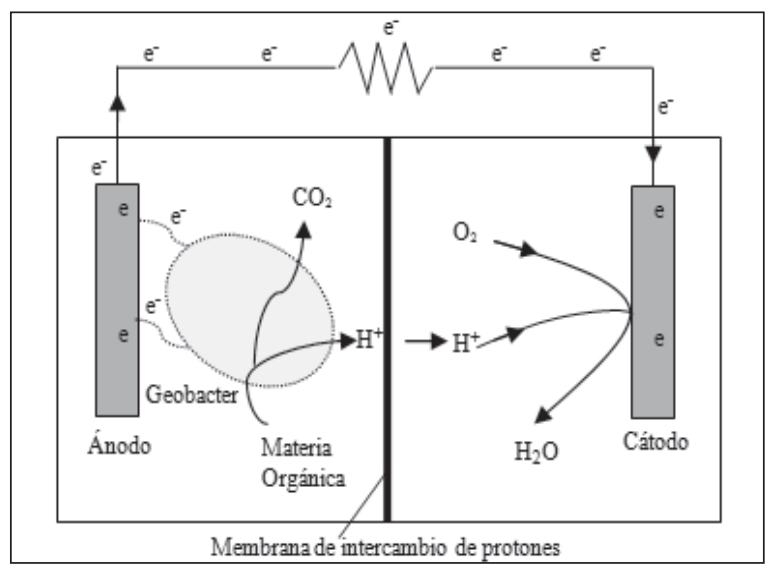

Fig. 5. Esquema básico de una Celda de Combustible Microbiana.

Tomada de: http://www.geobacter.org/publication-files/18564184.pdf

til es el carbón, disponible en placas de grafito compacto, barras o gránulos, ya que son relativamente económicos, fáciles de manipular y tienen un área de contacto definida. En el caso de una MFC de Geobacter, el grafito proporciona una superficie áspera, no sólo para que las células individuales se enlacen directamente al ánodo, sino que también permite a estas bacterias anclarse firmemente a la superficie por medio de Pili [27], [40], [41].

Reacción en el ánodo, donde el Geobacter interactúa con la materia orgánica "acetato" oxidándola completamente, de acuerdo con la Ec. (4).

$$
\mathrm{C}_{2} \mathrm{H}_{4} \mathrm{O}_{2}+2 \mathrm{H}_{2} \mathrm{O} \rightarrow 2 \mathrm{CO}_{2}+8 \mathrm{H}^{+}+8 e^{-}
$$

El oro se puede utilizar como material para fabricar el ánodo, debido a su alta conductividad eléctrica, maleabilidad y resistencia a la oxidación. Sin embargo, en unos experimentos que se realizaron con ánodos de oro [18], [40], [41] la corriente que se obtuvo es menor al compararla con electrodos de grafito, bajo condiciones similares.

Cátodo: los materiales con los que se deben construir los cátodos deben ser conductivos, biocompatibles y químicamente estables para soportar la interfaz donde se reduce el oxígeno puro con los protones y electrones, para formar agua, (Ec. (5)).

$$
2 \mathrm{O}_{2}+8 \mathrm{H}^{+}+8 e^{-} \rightarrow 4 \mathrm{H}_{2} \mathrm{O}
$$

La elección del material afecta de manera importante el desempeño de la MFC ya que limita la generación de corriente debido a que la reducción de oxígeno se puede producir a un ritmo lento y la densidad de corriente disminuye. Los materiales comúnmente utilizados son electrodos de grafito, filtro de grafito, papel carbón, tela de carbono, carbón vítreo reticulado [8], [42].

Membrana de intercambio de protones (proton exchange membrane (PEM)): Los materiales con los que se deben construir las membranas deben tener alta selectividad de protones, estabilidad y firmeza, para obtener el mejor funcionamiento en una MFC. La PEM ayuda a canalizar los protones en una sola dirección desde el ánodo hacia el cátodo, y la PEM más utilizada es el Nafion ${ }^{\circledR}$ 117 que tiene una alta puntuación para la selectividad de protones, pero tiene una estabilidad muy baja. Otra opción utilizada como PEM es el Ultrex que tiene una baja puntuación para la selectividad de protones, pero tiene una estabilidad muy alta. La diferencia entre las dos opciones tiene que ver directamente con la eficiencia energética y el costo [43].

\subsection{Celda de combustible microbiana de sedimento (Microbial Fuel Cell Sediment, MFCs)}

Las MFCs se caracterizan por emplear las bacterias de la familia Geobacter directamente en el hábitat natural como: lodos activados, lodos anaeróbicos, aguas residuales industriales, sedimentos marinos o sedimentos acuáticos, ricos en materia orgánica (Fig. 6). 


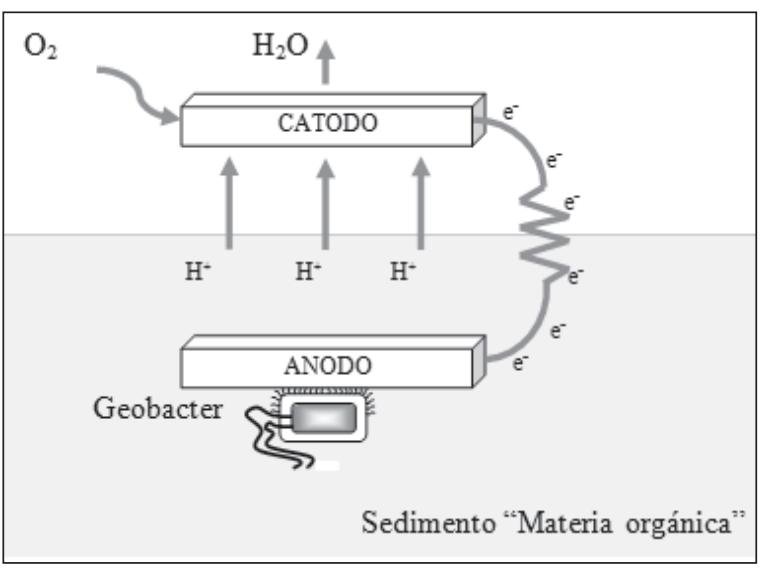

Fig. 6. Funcionamiento de una celda microbiana de sedimento [34].

Los materiales que componen este tipo de celdas son similares a los utilizados en una MFC.

\section{PRODUCCIÓN DE ELECTRICIDAD EMPLEANDO CELDAS DE COMBUSTIBLE MICROBIANA}

Las bacterias del género Geobacter pueden oxidar completamente compuestos sencillos como: el acetato, la glucosa, soluciones con alto contenido de materia orgánica como los residuos vegetales o las aguas residuales. La bacteria por medio de su metabolismo adquiere electrones del combustible y los transfiere en un buen porcentaje hacia un electrodo, durante este proceso no requiere ningún tipo de mediador gracias a los nanocables "Pili" que se conectan directamente sobre el electrodo. Las principales variables de los estudios realizados hasta la fecha están consignadas en la Tabla 3.

La electricidad que se obtiene en una celda de combustible microbiana por medio de bacterias es pequeña en comparación con otras fuentes de energía, no obstante, hay que tener en cuenta que esta tecnología es relativamente nueva y a pesar de esto ha avanzado hasta mil veces la eficiencia, ya que en la actualidad se produce una densidad de potencia por electrodo de $\mathrm{W} / \mathrm{m}^{2}$ frente a los $\mathrm{mW} / \mathrm{m}^{2}$ de las primeras experiencias. Conforme a los resultados se deduce que los electrodos han disminuido su tamaño hasta 800 veces, la densidad de corriente ha aumentado hasta 100 veces

Tabla 3. Resultados de los estudios realizados en mfc con Geobacter [8], [18], [27], [34].

\begin{tabular}{|c|c|c|c|c|c|c|}
\hline Año & $\begin{array}{c}\text { Volumen MFC } \\
(\mathbf{m L})\end{array}$ & $\begin{array}{c}\text { Área Ánodo } \\
\left(\mathbf{c m}^{2}\right)\end{array}$ & $\begin{array}{c}\text { Potencial eléctrico } \\
(\mathbf{V})\end{array}$ & $\begin{array}{c}\text { Corriente } \\
(\mathbf{m A})\end{array}$ & $\begin{array}{c}\text { Densidad de corriente } \\
\left(\mathbf{A} / \mathbf{m}^{2}\right)\end{array}$ & $\begin{array}{c}\text { Tipo } \\
\text { de electrodo }\end{array}$ \\
\hline 2003 & 450 & 61.2 & 0.2 & 0.4 & 0.065 & $\begin{array}{c}\text { Grafito Solido } \\
{[08]}\end{array}$ \\
\hline 2006 & 14 & 6.45 & 0.3 & 0.9 & 0.7 & $\begin{array}{c}\text { Fibra de carbono } \\
{[36]}\end{array}$ \\
\hline 2006 & 14 & 0.8 & 0.3 & 4.6 & $\begin{array}{c}\text { Fibra de carbono } \\
{[36]}\end{array}$ \\
\hline 2006 & 14 & 0.8 & 0.3 & 0.7 & 3.1 & $\begin{array}{c}\text { Grafito Solido } \\
{[36]}\end{array}$ \\
\hline 2008 & 6.4 & 7.8 & 0.3 & 2 & 3.1 & Oro [18] \\
\hline 2009 & 24 & 0.071 & 0.3 & 10 & 7.6 & $\begin{array}{c}\text { Tela de grafito } \\
{[27]}\end{array}$ \\
\hline
\end{tabular}


su producción en aproximadamente 10 años de investigación.

\section{SISTEMA PARA PRODUCIR ENERGÍA ELÉCTRICA EMPLEANDO CELDAS DE COMBUSTIBLE MICROBIANA}

Al igual que un sistema fotovoltaico aislado, es necesario tener un conjunto de elementos para promover energía eléctrica, los elementos básicos son: un elemento que transforme energía química de la materia orgánica en energía eléctrica, se conoce como celda de combustible microbiana; un elemento adicional que proteja la celda de procesos inadecuados de carga y descarga, se conoce como regulador o controlador de carga; y un elemento que pueda transformar corriente directa en corriente alterna, se conoce como inversor. Los elementos deben ir conectados como en la Fig. 7, ubicando como últimos elementos aquellos de consumo como: bombillas, radio, televisor, etc.

\subsection{Módulo de celda de combustible micro- biana}

Para realizar el módulo es necesario tener en cuenta el estudio que se hizo en una celda de

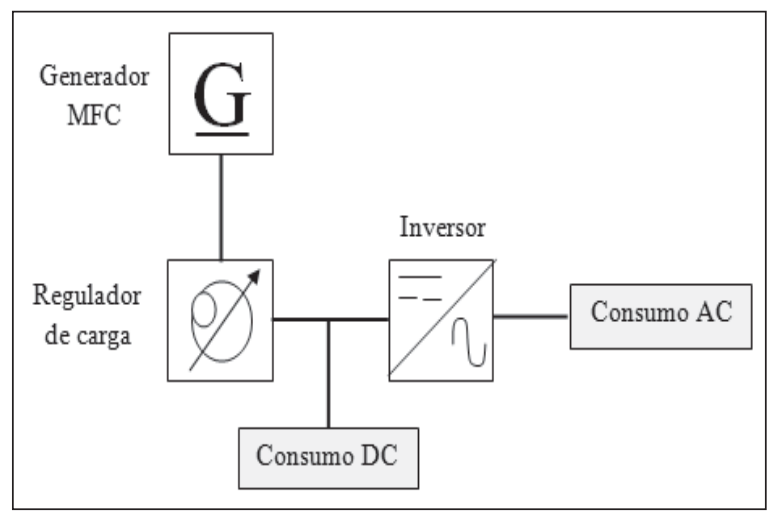

Fig. 7. Esquema simple de un sistema eléctrico con módulos de celdas de combustible microbiana. combustible microbiana con una biopelícula de Geobacter [27] cuyas dimensiones son: $2.5 \mathrm{~cm} \times$ $7.6 \mathrm{~cm} \times 1.3 \mathrm{~cm}$, equivalente a un volumen de 24 $\times 10^{-6} \mathrm{~m}^{3}$, bajo condiciones adecuadas. La MFC produce una corriente de $10 \mathrm{~mA}$, un voltaje de 0.3 VDC y una potencia de $3 \mathrm{~mW}$.

Con los datos se calcula para poder construir un generador eléctrico DC con bacterias para proveer de electricidad a un sistema eléctrico residencial o un sistema productivo (bombas de agua, cercas eléctricas, comunicación, iluminación, etc.).

El voltaje nominal requerido es de $12 \mathrm{VDC}$ con una potencia eléctrica de $100 \mathrm{~W}$.

Como cada celda suministra 0.3 VDC es necesario conectar $40 \mathrm{MFC}$ en serie, de tal manera que la suma de los voltajes suministren los 12 VDC como en la Ec. (6), así el equivalente se denomina sección.

$$
V_{S}=V_{1}+V_{2}+V_{3}+\ldots+V_{40}
$$

Para obtener la potencia eléctrica $P=V \times I$ se tiene en cuenta la corriente de $10 \mathrm{~mA}$ que provee cada MFC, por tanto cada sección puede aportar una potencia de $0.12 \mathrm{~W}$

Con el fin de producir la potencia requerida es necesario conectar 833 secciones en paralelo de tal

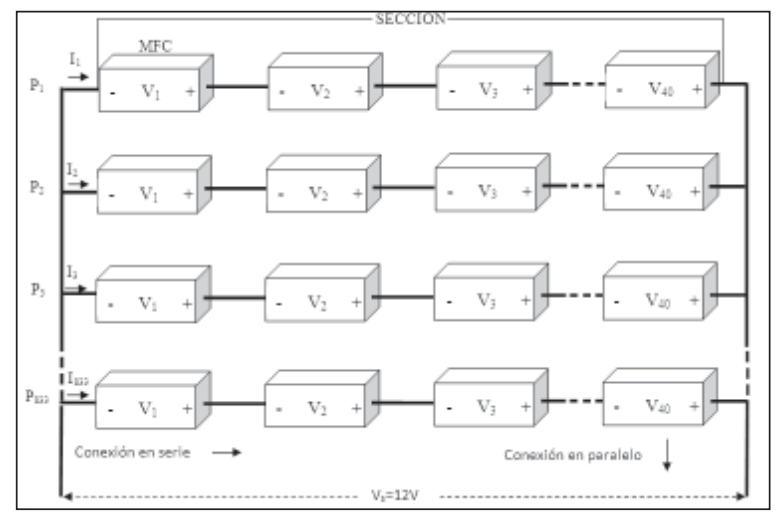

Fig. 8. Diagrama esquemático de un módulo compuesto por celdas de combustible microbiana. 
forma que la suma de las potencias alcancen los $100 \mathrm{~W}$ como en la Ec. (7).

$P=V_{S} \times I_{1}+V_{S} \times I_{2}+V_{S} \times I_{3}+\ldots+V_{S} \times I_{833}$

Finalmente, el módulo debe ser construido con un total de 33333 celdas que ocuparían un volumen aproximado de $0.8 \mathrm{~m}^{3}$ (Fig. 8).

\subsection{Regulador o controlador de carga}

Es un dispositivo electrónico que conecta los módulos a la carga, monitorea el sistema y establece los parámetros para que funcione correctamente. El parámetro fundamental es el voltaje, ya que se debe mantener constante en el tiempo. El uso de un controlador de carga aumenta la vida útil de los equipos.

\subsection{El Inversor}

Es un dispositivo que para transformar corriente continua generada por los módulos de $\mathrm{MCF}$ en corriente alterna con magnitud de $110 \mathrm{~V}$ ó $120 \mathrm{~V}$ a una frecuencia de $50 \mathrm{~Hz}$ o $60 \mathrm{~Hz}$. Lo anterior es necesario para lograr el funcionamiento de algunos aparatos eléctricos (lámparas, radios, televisores). Aunque hay aparatos eléctricos que no requieren este tipo de conversión porque funcionan a $12 \mathrm{~V}$ o $24 \mathrm{~V}$ DC.

\section{FUENTES DE ENERGÍA ELÉCTRICA}

Las fuentes de energía son los recursos energéticos en estado natural que a través de su extracción, refinación y transporte se pueden convertir en una energía o combustible fácilmente utilizable. Entre las fuentes de energía están las convencionales y las no convencionales.

Fuentes convencionales de energía, son las más utilizadas en el mundo para producir energía eléc- trica útil de forma habitual con una buena eficiencia, pero recientemente debido al agotamiento de la materia prima empleada, costos, espacio para la infraestructura y alteración del medio ambiente dejaron de ser viables, aunque desde las primeras centrales de energía hasta las actuales se ha establecido que estas fuentes han mejorado en su rendimiento, eficiencia, automatización y regulación, conservando el principio de funcionamiento, motivo por el cual se utilizan en gran porcentaje en todos los países. Las fuentes convencionales que más se aprovechan provienen de: energía hidráulica, energía térmica, energía nuclear.

Fuentes no convencionales de energía, aquellas con mínima participación en la generación de energía eléctrica en el mundo, debido a que son poco eficientes al transformar la fuente primaria en energía eléctrica, los gastos elevados de extracción y producción, no tiene mucho avance tecnológico por falta de investigación y la energía útil que se puede aprovechar es limitada, ya que no es muy eficiente la transformación de la fuente primaria a energía eléctrica. Las fuentes no convencionales que más se aprovechan provienen de energía eólica, energía biomasa, energía geotérmica, energía solar, entre otras.

Las fuentes de energías convencionales y no convencionales se pueden clasificar en energías renovables y no renovables. Las energías renovables son las que provienen de fuentes naturales aparentemente inagotables y autóctonas. El sol está en el origen de casi todas, por ejemplo: para la fuente de energía eólica induce en el planeta las diferencias de presión que dan origen a los vientos; para la fuente de la energía hidráulica ordena el ciclo del agua, con la evaporación del agua desde la superficie de ríos y océanos, a medida que se eleva el aire humedecido se enfría y el vapor se transforma en agua, las gotas se unen y forman una nube, luego caen por su propio peso dando paso a las lluvias; para la fuente energía de la biomasa, influye directamente en 
las plantas porque utilizan la energía radiante del sol como fuente de energía química para transformar el dióxido de carbono en compuestos orgánicos indispensables para su vida y crecimiento, parte de la energía química queda almacenada en forma de materia orgánica y puede recuperarse quemándola directamente o transformándola en combustible. Por otra parte, la energía suministrada por el sol es utilizada como fuente primaria y directa como energía solar que se puede transformar de dos maneras: la primera utiliza una parte del espectro electromagnético de la energía del sol para producir calor. A la energía obtenida se le llama energía solar térmica. La transformación se realiza mediante el empleo de colectores térmicos. La segunda, utiliza la otra parte del espectro electromagnético de la energía del sol para producir electricidad. A la energía obtenida se le llama energía solar fotovoltaica. La transformación se realiza por medio de módulos o paneles solares fotovoltaicos.

Para el año 2010 las fuentes de energía renovables alcanzaron el 13\% de la demanda mundial como energía primaria y adicionalmente aportaron un $18 \%$ de la energía que se emplea para producción de calor [44], [45].

Las fuentes de energías no renovables son las que provienen de elementos contenidos en la corteza terrestre en una cantidad limitada motivo por el cual una vez extraídas y consumidas en su totalidad no pueden sustituirse. Dentro de las energías no renovables se puede recurrir a dos tipos de combustibles: fósiles y nucleares. Los combustibles fósiles se originan de restos de seres vivos enterrados hace millones de años, que se transformaron bajo condiciones adecuadas de presión y temperatura, entre los cuales se pueden mencionar: el carbón, el petróleo y el gas natural. Los combustibles nucleares son aquellos elementos que liberan energía como resultado de una reacción nuclear entre los cuales se pueden mencionar: el uranio y el plutonio [46].

\subsection{Fuentes de energías convencionales}

\subsubsection{Energía hidráulica}

Es una fuente de energía renovable a causa de su regeneración por medios naturales, al explotarla es limpia, no utiliza residuos o sustancias contaminantes [47]. La energía hidráulica se obtiene a partir de la utilización de la energía potencial y cinética asociada con el caudal del agua, desniveles de alturas entre dos puntos del curso de un río o mareas. Una manera de obtener energía eléctrica con energía hidráulica es por medio de centrales hidroeléctricas que normalmente consta de una presa que acumula gran cantidad de agua, un aliviadero que libera el agua sobrante de forma controlada y una casa de máquinas. La casa de máquinas contiene conductos de transporte que hacen pasar el agua a través de unas turbinas que convierten el caudal lineal en caudal rotativo. El agua llega a alta velocidad y presión e incide en las palas de la turbina haciendo girar su eje. La turbina y el generador están interconectados. De este modo, la rotación de la turbina hace girar el rotor del generador eléctrico que es el encargado de producir energía eléctrica [48], [49]. El agua después de ser utilizada se devuelve al cauce del río, aprovechándose de nuevo.

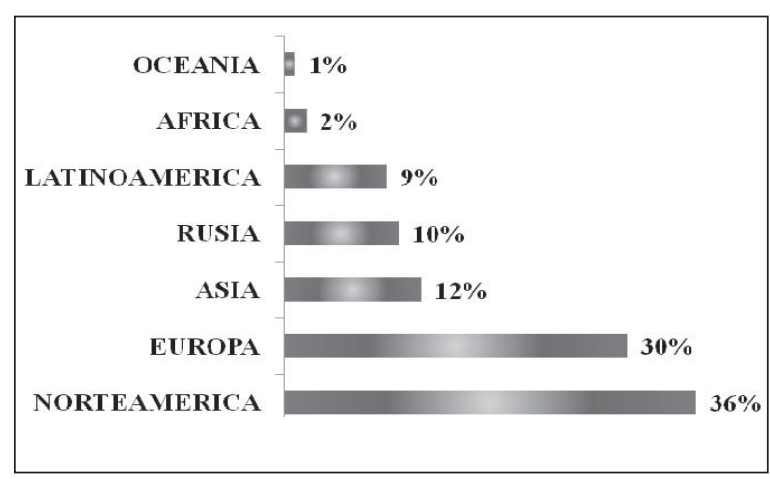

Fig. 9. Participación en porcentaje de capacidad de generación de energía hidroeléctrica en el mundo en el año 2010.

Tomada de: http://exterior.pntic.mec.es/ pvec0002/e_hidraulica 
La Fig. 9 muestra la distribución porcentual en generación de energía hidráulica en el mundo [50].

\subsubsection{Energía nuclear}

Es una fuente de energía no renovable, está localizada en los núcleos de los átomos y el combustible normalmente utilizado es el uranio. Los dos sistemas más investigados y trabajados para la obtención de energía aprovechable a partir de la energía nuclear de forma masiva son la fisión nuclear y la fusión nuclear. Fisión nuclear (se lanzan neutrones a gran velocidad sobre el núcleo de los átomos de uranio, que se dividen aproximadamente por la mitad. A su vez se liberan más neutrones que chocan con otros átomos de uranio vecinos y así sucesivamente en lo que se denomina reacción en cadena. Este proceso genera una gran cantidad de energía). Fusión nuclear (dos núcleos atómicos se unen para formar uno mayor. Este tipo de reacciones se originan normalmente en las estrellas y emiten cantidades enormes de energía. La dificultad reside en que se necesitan temperaturas muy altas para inducir la reacción).

Una central nuclear es una instalación para generar energía eléctrica a partir de energía nuclear. Se caracteriza por el empleo de combustible nuclear para producir calor, que a su vez es empleado para calentar agua y originar vapor que es inducido a través de unos conductos hacia las paletas de una turbina para hacerla girar sobre su eje. La turbina se encuentra unida por el eje a un generador eléctrico que es el encargado de producir energía eléctrica.

En la actualidad la energía nuclear es la fuente de energía más concentrada. Las centrales generan el 17\% (Fig. 10) de la energía eléctrica mundial [51], alrededor del planeta hay en funcionamiento 442 reactores nucleares con capacidad neta de 375 GW.

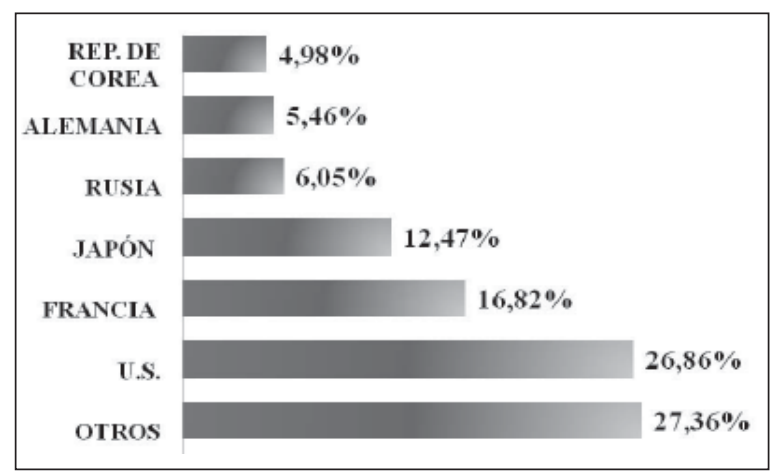

Fig. 10. Participación en porcentaje de capacidad de generación de energía nuclear en el mundo en el año 2010.

Tomada de: http://www.nei.org/resourcesandstats/documentlibrary/reliableandaffordableenergy/graphicsandcharts/worldnucleargenerationandcapacity/

\subsubsection{Energía térmica no renovable}

Es la energía que se produce mediante la combustión de (carbón, petróleo o gas natural). El calor generado al quemar el combustible se emplea para calentar agua en una caldera y convertirla en vapor, que es inducido a través de unos conductos hacia las paletas de una turbina para hacerla girar sobre su eje. La turbina se encuentra unida por el eje a un generador eléctrico que es el encargado de producir energía eléctrica. En el mundo las centrales térmicas generan el $41 \%$ de energía eléctrica con carbón térmico, y están distribuidas de acuerdo con Fig. 11.

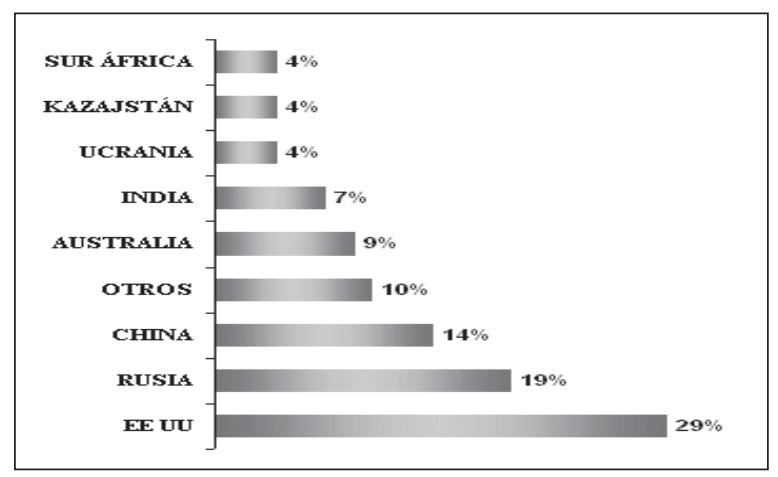

Fig. 11. Reservas en Porcentaje de carbón en el mundo por país en el año 2010. [52]. 


\subsection{Fuentes de energías no convencionales}

\subsubsection{Energía eólica}

Es una fuente de energía renovable y se obtiene a través de dos fuentes: el sol y el viento. El calentamiento desigual de la superficie terrestre por acción de la radiación solar, es el principal causante de las diferencias de presión que da origen a los vientos. La cantidad de energía que contiene el viento antes de pasar por un rotor en movimiento depende de tres parámetros: La velocidad del viento incidente, la densidad del aire y el área barrida por el rotor [53]. La central eólica es una instalación en donde la energía cinética del viento se puede transformar en energía mecánica de rotación. Para ello se instala una torre en cuya parte superior existe un rotor con múltiples paletas, orientadas en la dirección del viento. Las paletas o hélices giran alrededor de un eje horizontal que actúa sobre un generador eléctrico que es el encargado de producir energía eléctrica, Aerogenerador. Las centrales de energía eólica se pueden adaptar en la tierra o en el mar, aunque por condiciones estos proyectos se han ubicado en las zonas costeras y las cumbres de las montañas porque son las más favorables y mejor dotadas para el aprovechamiento del viento con fines energéticos [54].

En Colombia hay una central de generación de energía eólica, el parque Jepirachí, fue desarrollado por la Empresa Pública de Medellín (EPM) con la asistencia de la agencia técnica alemana de la cooperación (GTZ). El proyecto ubicado en la alta Guajira comenzó a operar en abril de 2004, con 15 aerogeneradores de 60 metros de alto que aportan una capacidad de 19,5 MW al Sistema Interconectado Nacional [54], [55].

En el año 2010 a nivel mundial las centrales de energía eólica alcanzaron una capacidad instalada de 194,4 GW, con un crecimiento del $22,5 \%$ equivalente a una capacidad de $35,8 \mathrm{GW}$ durante este año [56].

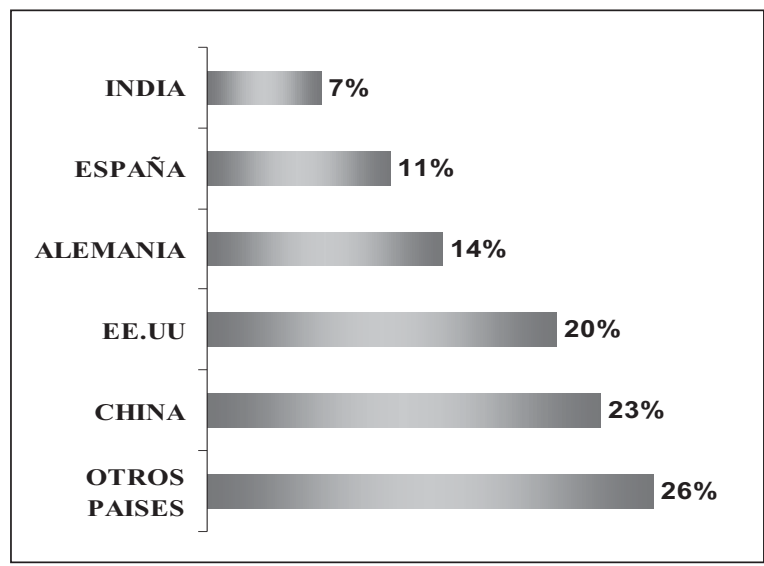

Fig. 12. Participación en porcentaje de capacidad de generación de energía eólica en el mundo en el año 2010.

Tomada de: http://ecopowerchile.com/ $b \log / ? p=2522$

El país de la república popular China tiene una capacidad instalada de $42,3 \mathrm{GW}$ en centrales de energía eólica siendo el primero en el mundo, superando a Estados Unidos de América, como en la Fig. 12.

\subsubsection{Energía solar fotovoltaica}

Es una fuente de energía renovable, consiste en el aprovechamiento de la energía del sol (radiación electromagnética) para producir electricidad. La transformación se realiza por medio de módulos o paneles solares fotovoltaicos [57]. Los módulos o paneles son placas rectangulares formadas por un conjunto de celdas fotovoltaicas protegidas por un marco de vidrio y aluminio anodizado, que tiene la función principal de soportar mecánicamente a las celdas fotovoltaicas y de protegerlas de los efectos degradantes de la intemperie, por ejemplo: humedad y polvo. Una celda fotovoltaica es el componente que capta la energía contenida en la radiación solar y la transforma en una corriente eléctrica, basado en el efecto fotovoltaico que produce una corriente eléctrica cuando la luz incide sobre algunos materiales. Las celdas 
fotovoltaicas son hechas principalmente con materiales semiconductores, de los cuales el silicio es el más usado. Una celda fotovoltaica tiene un tamaño de 10 x 10 centímetros y produce alrededor de un vatio a plena luz del día. La mayoría de los paneles fotovoltaicos consta de 36 celdas fotovoltaicas, con una capacidad promedio de $75 \mathrm{~W}$ con más o menos un 10\% de tolerancia [58]. Para aprovechar esta fuente de energía es necesario un sistema donde los módulos fotovoltaicos convierten en corriente eléctrica directa la energía solar que recibe durante el día; esta energía se transporta hasta un controlador de carga, la energía es almacenada en bacterias para abastecer las cargas durante la noche, en días de baja insolación o cuando el arreglo fotovoltaico no suple la demanda por sí solo. Si las cargas a alimentar son de corriente directa, esto puede hacerse directamente desde el arreglo fotovoltaico o desde la batería; si, en cambio, las cargas son de corriente alterna, la energía es enviada a un inversor.

La energía solar fotovoltaica se utiliza generalmente, en aquellos lugares donde no existe acceso a la red eléctrica convencional. La energía solar se encuentra disponible en todo el mundo.

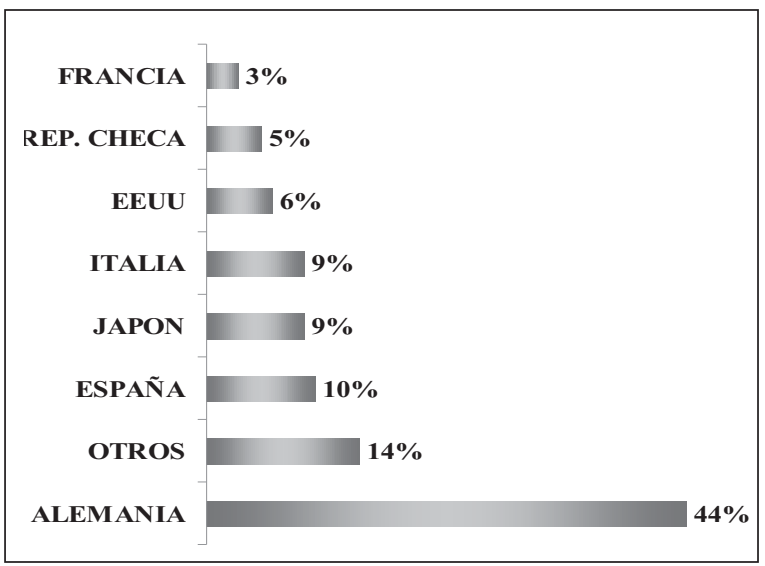

Fig. 13. Participación en porcentaje de capacidad de generación de Energía solar fotovoltaica en el mundo en el año 2010.

Tomadade: $h t$ tp://www.ren21.net/Portals/97/ documents/GSR/REN21_GSR2011.pdf
El mayor crecimiento del sector se produjo el año 2010 en Alemania (con una capacidad fotovoltaica acumulada de 9,8 GW) país líder mundial por capacidad instalada, seguido por España, Japón, Estados Unidos, Italia, República Checa y Bélgica (Fig. 13).

\subsubsection{Energía geotérmica}

Es una fuente de energía renovable, tiene su origen en la diferencia de altas temperaturas que existen en el interior de la Tierra y que van desde los $15^{\circ} \mathrm{C}$ de la superficie hasta los $4.000^{\circ} \mathrm{C}$ que rigen el núcleo. La energía geotérmica utilizada para producir electricidad es la proveniente del calor resultante de un gradiente térmico de las altas temperaturas desde el centro de la Tierra hasta la superficie terrestre. Las fuentes de calor que pueden intervenir son: rocas calientes que recubren un foco calorífico, sectores con actividad volcánica o zonas que producen gradientes térmicos debido a la fricción de las placas tectónicas. Un gradiente geotérmico es el aumento gradual de temperatura a medida que aumenta el descenso con respecto a la superficie terrestre, en promedio por cada 33 metros de profundidad el aumento es de $1^{\circ} \mathrm{C}$, en zonas volcánicas por cada 100 metros, el aumento de temperatura es de $20-30^{\circ} \mathrm{C}$ [59].

Con el fin de aprovechar esta fuente de calor se realizan perforaciones para inyectar agua a temperatura ambiente, la cual convertida en vapor producto de las altas temperaturas, por presión genera el movimiento de turbinas. Estas turbinas se encuentran unidas por el eje a un generador eléctrico, que es finalmente el encargado de producir energía eléctrica [60], [61].

En el mundo la capacidad instalada con esta fuente de energía primaria es aproximadamente de 44 GW. La República Popular China tiene una capacidad instalada de $8,7 \mathrm{GW}$ en centrales de energía 
geotérmica, siendo el primer país en el mundo, superando a Estados Unidos de América (Fig. 14).

Un buen sistema para generar energía eléctrica debe incluir como mínimo las ventajas expuestas en la Tabla 4 y enfocarse en producción de energía por demanda con gran capacidad y disponibilidad.

Un buen sistema para generar energía eléctrica debe evitar como mínimo las desventajas expuestas en la Tabla 5.

De acuerdo con los datos de la Tabla 6, un buen sistema para generar electricidad debe incluir ciertos requerimientos para favorecer el aspecto ambiental y social en aquellas regiones donde se implemente el sistema para la generación de energía eléctrica.

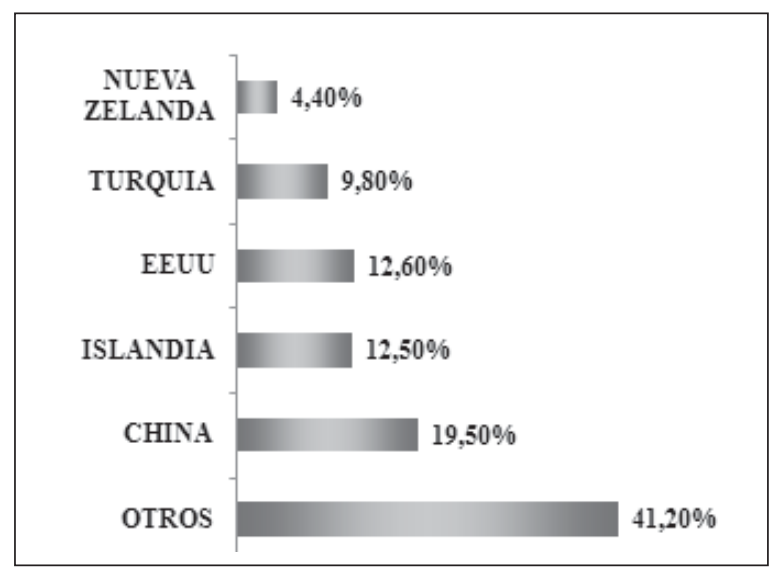

Fig. 14. Participación en porcentaje de capacidad de generación de Energía geotérmica en el mundo en el año 2010.

Tomada de: http://www.nationmaster.com/ graph/ene_geo_pow_use-energy-geothermal-power-use

Tabla 4. Ventajas en la producción de energía eléctrica con fuentes convencionales, no convencionales y bacterias

\begin{tabular}{|c|c|c|}
\hline Energías Convencionales & Energías no Convencionales & Energía por Bacterias \\
\hline $\begin{array}{l}\text { Tienen alta capacidad de producción de } \\
\text { energía eléctrica y son muy rentables }\end{array}$ & $\begin{array}{l}\text { La disposición del recurso se presenta } \\
\text { en un flujo constante para la producción } \\
\text { de energía a lo largo del año, indepen- } \\
\text { diente de variaciones del clima }\end{array}$ & $\begin{array}{l}\text { La conversión directa de sustancia orgá- } \\
\text { nica a electricidad permite altas eficien- } \\
\text { cias de conversión }\end{array}$ \\
\hline $\begin{array}{l}\text { Suministro permanente que no obliga a } \\
\text { almacenamientos ni se arriesga a desa- } \\
\text { bastecimientos }\end{array}$ & $\begin{array}{l}\text { Son energías limpias, renovables, múlti- } \\
\text { ples y abundantes }\end{array}$ & $\begin{array}{l}\text { Operan eficientemente a temperatura } \\
\text { ambiente, incluida temperaturas bajas }\end{array}$ \\
\hline $\begin{array}{l}\text { En general tienen larga vida de funcio- } \\
\text { namiento }\end{array}$ & $\begin{array}{l}\text { Se pueden instalar casi en cualquier si- } \\
\text { tio y son sistemas silenciosos }\end{array}$ & $\begin{array}{l}\text { La fuente primaria son por lo general } \\
\text { desperdicios orgánico producidos por } \\
\text { los seres vivos, que solo alteran el me- } \\
\text { dio ambiente }\end{array}$ \\
\hline Tiene un bajo costo de mantenimiento & $\begin{array}{l}\text { Mejora la economía de la región donde } \\
\text { se implementa }\end{array}$ & $\begin{array}{l}\text { Este tipo de baterías no requieren man- } \\
\text { tenimiento y pueden funcionar varios } \\
\text { años }\end{array}$ \\
\hline $\begin{array}{l}\text { Los proyectos se desarrollan por lo ge- } \\
\text { neral cerca de zonas del suministro de } \\
\text { combustible }\end{array}$ & $\begin{array}{l}\text { Estímulos a las inversiones y algunas } \\
\text { ventajas para fomentar el desarrollo de } \\
\text { las energías renovables no convencio- } \\
\text { nales }\end{array}$ & $\begin{array}{l}\text { Ofrecen una alternativa renovable y lim- } \\
\text { pia para la generación de energía eléc- } \\
\text { trica, una vez que el suministro de com- } \\
\text { bustibles fósiles se agote o antes si las } \\
\text { medidas para reducir el calentamiento } \\
\text { global llevan a medidas drásticas para } \\
\text { reducir el uso de combustibles fósiles }\end{array}$ \\
\hline $\begin{array}{l}\text { Han sido los grandes protagonistas del } \\
\text { impulso industrial }\end{array}$ & $\begin{array}{l}\text { Las energías renovables evitan la de- } \\
\text { pendencia de unas regiones a otras, ya } \\
\text { que son autóctonas }\end{array}$ & $\begin{array}{l}\text { La infraestructura que pueden utilizar } \\
\text { estos sistemas no requiere un territorio } \\
\text { definido }\end{array}$ \\
\hline
\end{tabular}


Tabla 5. Desventajas en la producción de energía eléctrica con fuentes convencionales, no convencionales y bacterias

\begin{tabular}{|c|c|c|}
\hline Energías Convencionales & Energías no Convencionales & Energía por Bacterias \\
\hline $\begin{array}{l}\text { Los combustibles fósiles son finitos; existen } \\
\text { sólo en un número limitado de países y man- } \\
\text { tienen incertidumbre respecto a los precios } \\
\text { actuales }\end{array}$ & $\begin{array}{l}\text { Bajo rendimiento de conversión de } \\
\text { fuente primaria a energía eléctrica }\end{array}$ & $\begin{array}{l}\text { Puede ser una molestia para los se- } \\
\text { res humanos debido al papel que } \\
\text { desempeñan en la corrosión en las } \\
\text { estructuras con hierro tales como: } \\
\text { tuberías, sistemas de calefacción y } \\
\text { aquellos aparatos que se compo- } \\
\text { nen de hierro }\end{array}$ \\
\hline $\begin{array}{l}\text { Costos iníciales de infraestructura muy eleva- } \\
\text { dos }\end{array}$ & $\begin{array}{l}\text { En general la inversión inicial es } \\
\text { muy costosa y no puede competir la } \\
\text { rentabilidad de las convencionales }\end{array}$ & $\begin{array}{l}\text { Los costos son muy elevados debi- } \\
\text { do a que están en etapa de inves- } \\
\text { tigación }\end{array}$ \\
\hline $\begin{array}{l}\text { Cuando se producen accidentes puedes ser } \\
\text { catastróficos }\end{array}$ & $\begin{array}{l}\text { Para generar energía eléctrica con } \\
\text { gran capacidad se requieren ex- } \\
\text { tensiones considerables de terreno }\end{array}$ & $\begin{array}{l}\text { Los resultados obtenidos hasta el } \\
\text { momento no son competitivos para } \\
\text { generar energía por demanda }\end{array}$ \\
\hline $\begin{array}{l}\text { Riesgos de accidentes durante la extracción y } \\
\text { el transporte de los combustibles; gas, petró- } \\
\text { leo, carbón, residuos nucleares, entre otras }\end{array}$ & $\begin{array}{l}\text { Desde el punto de vista estético, } \\
\text { produce un impacto visual desfavo- } \\
\text { rable, ya que por sus características } \\
\text { precisa sitios como: cerros, colinas, } \\
\text { zonas costeras }\end{array}$ & $\begin{array}{l}\text { La búsqueda de residuos aptos } \\
\text { para el consumo energético puede } \\
\text { afectar el reciclaje normal de los } \\
\text { elementos presentes en la basura }\end{array}$ \\
\hline $\begin{array}{l}\text { Las centrales de energía se instalan lejos de } \\
\text { los centros de consumo y exige la construcción } \\
\text { de un sistema de transmisión eléctrico, lo que } \\
\text { significa un aumento en la inversión, en costos } \\
\text { de mantenimiento y en pérdida de energía }\end{array}$ & $\begin{array}{l}\text { Son fuentes con disponibilidad li- } \\
\text { mitada, solo se dispone durante } \\
\text { ciertas horas y se debe esperar que } \\
\text { haya suficiente almacenamiento }\end{array}$ & \\
\hline
\end{tabular}

Tabla 6. Impacto ambiental y social en la producción de energía eléctrica con fuentes convencionales, no convencionales y bacterias

\begin{tabular}{|l|l|l|}
\hline Energías Convencionales & Energías no Convencionales & Energía por Bacterias \\
\hline $\begin{array}{l}\text { Producen emisiones de dióxido de } \\
\text { carbono y otros gases que conta- } \\
\text { minan la atmósfera que causan el } \\
\text { efecto invernadero y por tanto el } \\
\text { calentamiento global }\end{array}$ & $\begin{array}{l}\text { Las emisiones de dióxido de carbo- } \\
\text { noy otros gases contaminantes a la } \\
\text { atmósfera son menores que las con- } \\
\text { vencionales }\end{array}$ & $\begin{array}{l}\text { Contribuye a la fijación del CO2 y a la correc- } \\
\text { ción del efecto invernadero }\end{array}$ \\
\hline $\begin{array}{l}\text { Algunas emiten residuos peligro- } \\
\text { sos que contaminan el ambiente y } \\
\text { afectan la fauna, la flora y los seres } \\
\text { humanos a su alrededor }\end{array}$ & $\begin{array}{l}\text { La fuente primaria en algunos casos } \\
\text { es inagotable, frena el agotamiento } \\
\text { de combustibles fósiles y contribuye } \\
\text { a evitar el cambio climático }\end{array}$ & $\begin{array}{l}\text { La fuente primaria es inagotable ya que se } \\
\text { emplea materia orgánica además contribuye } \\
\text { bio climático }\end{array}$ \\
\hline $\begin{array}{l}\text { Con la construcción de ríos y a evitar el cam- } \\
\text { transmisión provocan efectos ne- } \\
\text { gativos en los bosques y afectan } \\
\text { la fauna local, causando una severa } \\
\text { modificación del paisaje }\end{array}$ & $\begin{array}{l}\text { Aplicación para iniciativas de coge- } \\
\text { neración, donde se empleen resi- } \\
\text { duos o desechos }\end{array}$ & $\begin{array}{l}\text { No requiere proceso de combustión o una } \\
\text { etapa transformación térmica, supone, } \\
\text { desde el punto de vista medioambiental, un } \\
\text { procedimiento muy favorable por ser limpio }\end{array}$ \\
\hline
\end{tabular}




\begin{tabular}{|l|l|l|}
$\begin{array}{l}\text { Aspectos que alteran el medio am- } \\
\text { biente como el ruido, cambio de } \\
\text { temperatura de las aguas, cenizas } \\
\text { residuos de combustión y residuos } \\
\text { radioactivos }\end{array}$ & $\begin{array}{l}\text { Algunas especies animales perciben } \\
\text { limitada su hábitat y supervivencia, } \\
\text { llevando a muchos a la extinción }\end{array}$ & $\begin{array}{l}\text { Como son bacterias reductoras de sulfato, } \\
\text { durante este proceso, liberan sulfuro de hidró- } \\
\text { geno con mal olor. En cantidades muy peque- } \\
\text { nas, sulfuro de hidrógeno o gas de alcanta- } \\
\text { rilla, es relativamente inofensiva, irritación de } \\
\text { los ojos, tos y líquido en los pulmones puede } \\
\text { ocurrir, pero desaparece un par de semanas } \\
\text { después del fin de la exposición }\end{array}$ \\
\hline $\begin{array}{l}\text { Los empleos ocasionados son tem- } \\
\text { porales y muy pocos respecto a su } \\
\text { volumen de negocio }\end{array}$ & $\begin{array}{l}\text { Generación considerable de empleo } \\
\text { respecto a su volumen de negocio } \\
\text { en zonas rurales, estabilidad y mejo- } \\
\text { ra los ingresos en la región }\end{array}$ & $\begin{array}{l}\text { Generación de empleo e ingresos ya que se } \\
\text { puede implementar en aquellas regiones don- } \\
\text { de no llega la red eléctrica. }\end{array}$ \\
\hline $\begin{array}{l}\text { El desplazamiento y desarraigo } \\
\text { de habitantes de las zonas anega- } \\
\text { das, con los conflictos personales } \\
\text { y sociales que esto trae consigo y } \\
\text { en ciertas zonas promueve la pros- } \\
\text { titución. }\end{array}$ & $\begin{array}{l}\text { Se trata de fuentes de energías idó- } \\
\text { neas para poblaciones que se hallen } \\
\text { en localizaciones remotas, lugares a } \\
\text { los que no llegan las redes conven- } \\
\text { cionales de suministro de energía }\end{array}$ & $\begin{array}{l}\text { No requiere la construcción de líneas de } \\
\text { transmisión que causan una severa modifica- } \\
\text { ción del paisaje }\end{array}$ \\
\hline
\end{tabular}

\section{APLICACIONES BÁSICAS DEL GEOBACTER}

De acuerdo con las características internas de las bacterias de la familia Geobacter, los científicos han determinado una serie de oficios donde la bacteria puede y será de gran utilidad, (Fig. 15).

\subsection{Biodegradación y biorremediación}

El término biodegradación significa "descomponer" materiales ambientalmente peligrosos mediante la acción de organismos vivos (bacterias). Por tanto antes que el proceso pueda ocurrir, debe existir una acumulación de sustancias químicas tóxicas o potencialmente tóxicas que necesitan ser reducidas o eliminadas.

Las prácticas de biorremediación consisten en una biotecnología que usa bacterias para eliminar sustancias contaminantes que pueden ser de naturaleza física, biológica o química y pueden aparecer en todos los estados físicos (sólido, lí-

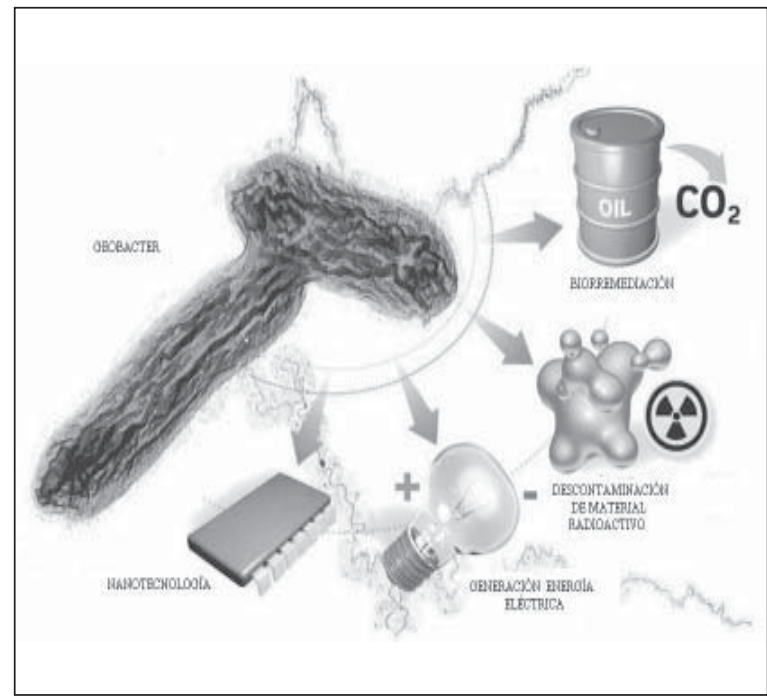

Fig. 15. Representación del Geobacter y sus aplicaciones.

Tomada de: http://mojaenergia.pl/strony/1/ i/417.php

quido o gaseoso) en un determinado lugar, sea este suelo, sedimento, fango o mar. La biorremediación le da una ayuda al medio ambiente en la mejora de los ecosistemas dañados, aceleran- 
do dichos procesos naturales. Lo que hacen las bacterias es degradar los desechos en productos que no alteren el medio ambiente, además de concentrar e inmovilizar sustancias tóxicas, metales pesados; minimizar desechos industriales y rehabilitar áreas afectadas con diversos contaminantes. Para lograr estos beneficios es necesario suministrar a los microorganismos ciertas condiciones ambientales, tales como: humedad, cantidad de oxígeno apropiado, $\mathrm{pH}$ y temperatura adecuada, estas condiciones permiten el desarrollo y multiplicación de las bacterias. De acuerdo con los factores descritos, el proceso se puede llevar a cabo mediante dos procedimientos: biorremediación in situ consiste en tratar las aguas, suelos o arenas contaminadas, sin sacarlas del lugar en el que se encuentran, está relacionado con tratamientos que no requieren excavación del sitio contaminado; biorremediación ex situ, son los procesos de tratamiento realizados tras excavar el suelo o el material contaminado, se realiza en un lugar diferente al lugar en que se encuentra el residuo, se maneja en un sistema controlado con un tipo de biorreactor o celda de combustible microbiana, consiste en la reducción de la concentración de contaminantes derivados del petróleo de suelos excavados mediante el uso de la biodegradación, las ventajas de estos procedimientos frente a los primeros, reside en la posibilidad de optimizar mejor los parámetros microbiológicos, así como el control del proceso a contraprestación de un precio superior.

El Geobacter puede degradar con relativa facilidad petróleo y sus derivados; benceno, tolueno, acetona, pesticidas, herbicidas, éteres, alcoholes simples, entre otros. Los metales pesados como uranio, cadmio y mercurio no son biodegradables, pero estas bacterias pueden concentrarlos de tal manera que precipita los metales para que sean eliminados fácilmente. La especie Geobacter ha sido utilizada para promover la biorremediación in situ de agua subterránea contaminada con uranio [62], [63].
En el Departamento de Energía de Estados Unidos han utilizado bacterias del género Geobacter y hongos para la remediación del río Rifle Mill en Western Colorado de Estados Unidos, que en tiempo pasado se encontraba con altos índices de contaminación de material radiactivo "uranio VI", mineral utilizado para fabricar armas nucleares. En el proceso los microorganismos que se emplearon han logrado reducir el material contaminante a uno menos tóxico, el uranio IV que es soluble en el agua, por tanto fácil de aislar. En el transcurso de 5 años se logró recuperar cerca de $80 \%$ del río. En la actualidad los estudios recientes sugieren que el Geobacter puede en 50 días, reducir en un $70 \%$ el uranio radiactivo insoluble en un material neutro, un acuífero subterráneo contaminado [64], [65].

\subsection{Nanotecnología}

La nanotecnología es el estudio, diseño, elaboración, manipulación y aplicación de materiales; aparatos y sistemas funcionales a través de la explotación de fenómenos, propiedades y control de la materia en una escala tan pequeña como un nanómetro. El desarrollo de esta tecnología tal vez permita en un futuro no muy lejano solucionar problemas de toda índole como: almacenamiento, producción y conversión de energía eléctrica; armamento y sistemas de defensa; producción agrícola; tratamiento y remediación de aguas y de la contaminación atmosférica; diagnóstico y tratamiento de enfermedades, monitorización de la salud, reconstrucción celular, implantes cerebrales; sistemas de administración de fármacos; procesamiento de alimentos; fabricación y construcción de edificios e infraestructuras; detección y control de plagas; control de desnutrición en lugares pobres; informática; alimentos transgénicos, etc. Para obtener estos beneficios es necesario cables ultra finos y muy pequeños, a menudo llamados nanocables que normalmente se pueden hacer de materiales como metales, silicio y carbono; pero 
su construcción es difícil y de muy alto costo. Sin embargo, el Geobacter produce sobre un costado de su célula unos nanocables denominados Pili que se pueden extraer y utilizar como conductores en diferentes dispositivos, por tanto, se podría cultivar miles de millones de células de Geobacter en un laboratorio para producir los nanocables microbianos. Más aún, alterando la secuencia de ADN de las bacterias se pueden nanocables con diferentes propiedades y funciones [43], [66], con el fin de disminuir costos para los dispositivos creados con nanotecnología.

\subsection{Producción de hidrógeno}

El hidrógeno es un elemento químico básico, ligero, incoloro, inodoro y no tóxico, presente en todo el planeta, puede ser comprimido y almacenado en forma líquida o gaseosa por varios meses hasta que se requiera, es más ligero que el aire. Bajo nivel de contaminantes atmosféricos en especial por la ausencia de $\mathrm{CO}_{2}$, ya que su único producto luego de la combustión puede ser agua. El hidrógeno representa energía almacenada que se puede quemar como cualquier combustible para producir calor, directamente como combustible de motores o para la generación de energía eléctrica mediante turbinas de gas y ciclos combinados. El hidrógeno no es una energía primaria, no se consigue fácil en la naturaleza por lo tanto es preciso obtenerlo mediante la utilización de una celda de combustible microbiana. La MFC consiste básicamente en dos compartimentos, anódico y catódico, que están separados por una membrana permeable de intercambio de protones. El compartimiento anódico se debe conservar en condiciones anaeróbicas donde una biopelícula del Geobacter sobrepuesto en el ánodo oxida la materia orgánica y genera dióxido de carbono, protones y electrones. Los electrones viajan a través de una resistencia que conecta el ánodo y el cátodo, originando una pequeña corriente que puede ser medida y utilizada para realizar trabajo. Los protones son trans- feridos por medio de la membrana permeable al compartimiento catódico, en esta cámara se combinan los $\mathrm{H}^{+}$y los electrones, generando $\mathrm{H}_{2}$.

\section{CONCLUSIONES}

El género Geobacter tiene características que se pueden controlar fácilmente en celdas de combustible microbiana para su crecimiento, desarrollo y producción de electricidad, por tanto si se puede controlar la producción de bacterias controlamos la fuente energética, lo que nos permite evitar el uso de combustibles fósiles y nucleares y sus consecuencias en los aspectos ambientales y sociales. Aunque se debe resaltar que el desarrollo de esta tecnología está en sus inicios por lo que los diseños deben de ser estudiados y optimizados para ofrecer resultados competitivos.

Con la estimación que se realizó sobre el sistema de celdas de combustible microbiana se determinó que el potencial de producción es el requerido para proveer de energía necesaria a una vivienda, en consecuencia, esta forma de generar energía se convierte en una solución para las zonas no interconectadas a la red eléctrica en Colombia o cualquier otra región.

Los nanocables "Pili" que hacen parte del Geobacter pueden revolucionar abruptamente la electrónica, abriendo un horizonte propicio para disminuir considerablemente el tamaño de instrumentos y maquinarias que pueden solucionar problemas de toda índole a la humanidad.

Es un hecho que la forma de producción actual puede llevar a la especie humana a su desaparición, lo que implica que se deben desarrollar nuevas tecnologías que permitan mitigar el impacto de los avances científicos, tecnológicos y técnicos del ser humano, lo que se quiere decir que se deben reemplazar artefactos como el motor a base de combustible fósil y las energías convencionales, por tanto, toma fuerza la propuesta de utilizar bacterias con fines energéticos. 
Utilizar microorganismos con fines energéticos debería convertirse en un desafío científico que muestre el compromiso de la ciencia en general, de la ingeniería y de la microbiología por implementar tecnologías que no afecten el medio ambiente, y logren suplir la demanda de energía eléctrica presente y futura, por eso se requiere que los gobiernos de países industrializados y emergentes promuevan y financien este tipo de investigaciones, ya que posteriormente será un beneficio para toda la humanidad.

Una tecnología basada en bacterias puede generar electricidad, depurar aguas residuales y a la vez producir hidrógeno lo que la hace bastante atractiva para tratamientos de biorremediación in situ, generación de energía eléctrica y combustibles. Además esta tecnología es autóctona, no produce dióxido de carbono, no afecta directamente al ser humano y lo más importante la fuente primaria son por lo general desperdicios orgánicos producidos por los seres vivos, que habitualmente solo alteran el medio ambiente.

\section{RECONOCIMIENTO}

Bioquímico. Jesús Arnoldo Daza Figueredo M.Sc. Evaluador del artículo, por sus aportes al mismo.

Geóloga. Elsa Adriana Cárdenas Quiroga M.Sc. por sus aportes en Geología.

\section{REFERENCIAS}

[1] A, Muktak, et, ál. "The genome sequence of Geobacter metallireducens: features of metabolism, physiology and regulation common and dissimilar to Geobacter sulfurreducens", Lawrence Berkeley National Laboratory, 2009.

[2] R. Lovley, "Dissimilatory Fe(III) and Mn(IV) Reduction", Microbiological Reviews, vol. 55, pp. 259-287, 1991.

[3] D. R. Lovley, "Dissimilatory Metal Reduction", Applied And Environmental Microbiology, vol 47. pp. 263-290, 1993.

[4] D. Lovley, "Humic Substances as a Mediator for Microbially Catalyzed Metal Reduction", Acta Hydrochin Hydrobiol, vol. 26, no. 3, pp. 152-157, 1998.

[5] K. Gregory, D. Bond and D. Lovley, "Graphite Electrodes as Electron Donors for Anaerobic Respiration", Environmental Microbiology, vol. 6, no. 6, pp. 596-604, 2004.
[6] E. J. Phillips, D. R. Lovley and E. E. Roden, "Composition of Non-Microbially Reducible Fe(III) in Aquatic Sediments", Applied And Environmental Microbiology, vol. 59, no. 8, pp. 2727-2729, 1993.

[7] B. Lin, M. Braster, B. M. Van Breukelen, H. W. Van Verseveld, Hans V. Westerhoff and W. F. Roling, "Geobacteraceae Community Composition Is Related to Hydrochemistry and Biodegradation in an Iron-Reducing Aquifer Polluted by a Neighboring Landfill", Applied And Environmental Microbiology, vol. 71, no. 10, pp. 5983-5991, 2005.

[8] D. R. Bond and D. R. Lovley, "Electricity Production by Geobacter sulfurreducens Attached to Electrodes", Applied And Environmental Microbiology, vol. 69, no 3, pp. 1548-1555, 2003.

[9] J. D. Wall and L. R. Krumholz, "Uranium Reduction", The Annual Review of Microbiology, vol.60, pp. 149-166, 2006. 
[10] K. B. Gregory and D. R. Lovley, "Remediation and Recovery of Uranium from Contaminated Subsurface Environments with Electrodes", Environ Sci Technol, vol. 39, no. 22, pp. 8943-8947, 2005.

[11] S. Strycharz, T. Woodard, J. Johnson, K. Nevin, R. Sanford, F. Loffler and D. Lovley, "Graphite Electrode as a Sole Electron Donor for Reductive Dechlorination of Tetrachlorethene by Geobacter lovleyi", Applied and Environmental Microbiology, vol. 74, no. 19, pp. 5943-5947, Oct., 2008.

[12] G. Reguera, R. Pollina, J. Nicoll and D. Lovley, "Possible Nonconductive Role of Geobacter sulfurreducens Pilus Nanowires in Biofilm Formation", American Society for Microbiology, vol. 189, no. 5, pp. 21252127, 2007.

[13] J. Roach, "Rust-Breathing Bacteria: Miracle" Microbes", National Geographic News, pp. 1-7, 2004.

[14] D. E. Holmes, K. P. Nevin and D. R. Lovley, "Comparison of $16 \mathrm{~S}$ rRNA, nifD, recA, gyrB, rpoB and fusA genes within the family Geobacteraceae fam. Nov", International Journal of Systematic and Evolutionary Microbiology, vol 54, no. 5, pp. 1591-1599, 2004.

[15] E. S. Shelobolina, et ál, "Geobacter Pickeringii sp. nov., Geobacter Argillaceus sp. nov. and Pelosinus Fermentans gen. nov., sp. nov., Isolated from Subsurface Kaolin Lenses", International Journal of Systematic and Evolutionary Microbiology, vol. 57. no. 1, pp. 126-135, 2007.

[16] E. S. Shelobolina, H. A. Vrionis, R. H. Findlay and D. R. Lovley, "Geobacter Uraniireducens sp. nov., Isolated from Subsurface Sediment Undergoing Uranium
Bioremediation", International Journal of Systematic and Evolutionary Microbiology, vol. 58, no. 5, pp. 1075-1078, 2008.

[17] K. L. Straub and B. E. Buchholz-Cleven, "Geobacter Bremensis sp. nov. and Geobacter Pelophilus sp. nov., two Dissimilatory Ferric-iron-reducing Cacteria", International Journal of Systematic and Evolutionary Microbiology, vol. 51, no. 5, pp. 1805-1808, 2001.

[18] H. Richter, K. McCarthy, K. P. Nevin, J. P. Johnson, V. M. Rotello and D. R. Lovley, Electricity Generation by Geobacter Sulfurreducens Attached to Gold Electrodes, Departments of Microbiology and Chemistry, University of Massachusetts, Amherst, Massachusetts, vol. 24, no. 8, pp. 1-4, 2008.

[19] O. Stukalov, A. Korenevsky, T. J. Beveridge and J. R. Dutcher, "Use of Atomic Force Microscopy and Transmission Electron Microscopy for Correlative Studies of Bacterial Capsules", Applied And Environmental Microbiology, vol. 74, no. 17, pp. 5457-5465, 2008.

[20] G. Reguera, K. D. McCarthy, T. Mehta, J. S. Nicoll, M. T. Tuominen and D. R. Lovley, "Extracellular Electron Transfer Via Microbial Nanowires", Nature, vol. 435, pp. 1098-1101, 2005.

[21] D.E. Holmes, D.R. Bond, R.A. O’Neil, C.E. Reimers, L.R. Tender and D.R. Lovley, "Microbial Communities Associated with Electrodes Harvesting Electricity from a Variety of Aquatic Sediments", Electrodeassociated Communities, vol. 48, no. 2, pp. 178-190, 2004.

[22] Jun Sun, et ál, "Genome-scale Constraintbased Modeling of Geobacter Metallire- 
ducens", Departments of Microbiology and Chemistry, University of Massachusetts, Amherst, Massachusetts, vol. 3, pp. 1-44, 2009.

[23] D. C. Joyner, J. L. Fortney, R. Chakraborty and T. C. Hazen, "Adaptation of the Biolog Phenotype MicroArrayTM technology to profile the Obligate Anaerobe Geobacter Metallireducens", Lawrence Berkeley National Lab, pp. 3134-3137, 2010. [En línea] Disponible en: http://escholarship.org/uc/ item $/ 3$ wr $7 \mathrm{t} 4 \mathrm{cp}$

[24] W. C. Lin, M. V. Coppi and D. R. Lovley, "Geobacter sulfurreducens Can Grow with Oxygen as a Terminal Electron Acceptor", Applied And Environmental Microbiology, vol. 70, no. 4, pp. 2525-2528, 2004.

[25] D. Holmes, et ál, "Microarray and Genetic Analysis of Electron Transfer to Electrodes in Geobacter Sulfurreducens", Environmental Microbiology, vol. 8, no. 10. pp. 1805-1820. 2006.

[26] D.R. Lovley, "Analysis of the Genetic Potential and Gene Expression of Microbial Communities Involved in the In Situ Bioremediation of Uranium and Harvesting Electrical Energy from Organic Matter", Journal of Integrative Biology, vol. 6, no. 4, pp. 331-339, 2002.

[27] H. Yia, et ál, "Selection of a variant of Geobacter Sulfurreducens with Enhanced Capacity for Current Production in Microbial Fuel Cells", Biosensors and Bioelectronics, vol. 24, no. 12. pp. 3498-3503, 2009.

[28] W. M., Marta, Orlando M., Quiroz L. José D., Lina M., "Mapa Hidrogeológico del Departamento de Córdoba", Instituto Colombiano de Geología y Minería, 2004.
[29] Salinas Echeverri, R., "Mapa Hidrogeológico del departamento de Sucre", Instituto Colombiano de Geología y Minería, 2002.

[30] C. A. Salgado, "Microbial Fuel Cells Powered by Geobacter Sulfurreducens", Basic Biotechnology, vol. 5, no. 1, pp. 96-101, 2009.

[31] M. Piccolino, "Animal electricity and the birth of Electrophysiology: The Legacy of Luigi Galvani", Brain Research Bulletin, vol. 46, no. 5, pp. 381-407, 1998.

[32] A. K. Shukla, P. Suresh, S. Berchmans and A. Rajendran, "Biological Fuel Cells and Their Applications", Current Science, vol. 87, no. 4, pp. 455-468, 2004.

[33] Z. Du, H. Li and T. Gu, "A State of the Art Review on Microbial Fuel Cells: A Promising Technology for Wastewater Treatment and Bioenergy", Biotechnology Advances, vol. 25, no. 5, pp. 464-482, 2007.

[34] D. R. Lovley, "Bug Juice: Harvesting Electricity with Microorganisms", Nature Publishing Group, vol. 4, pp. 497-508, 2006.

[35] Z. He and L. Angenent, "Application of Bacterial Biocathodes in Microbial Fuel Cells", Department of Energy, Environmental and Chemical Engineering, vol. 18, no.19-20, pp. 2009-2015, 2006.

[36] K. P. Nevin, et ál, "Power Output and Columbic Efficiencies From Biofilms of Geobacter Sulfurreducens Comparable to Mixed Community Microbial Fuel Cells", Environmental Microbiology, vol. 10, no. 10, pp. 1462-1472, 2008.

[37] K. Rabaey and W. Verstraete, "Microbial Fuel Cells: Novel Biotechnology for En- 


\section{|re-creaciones}

ergy Generation", TRENDS in Biotechnology, vol. 23, no. 6, pp. 291-298, 2005.

[38] Z. He, H. Shao and L. Angenent, "Increased Power Production From a Sediment Microbial Fuel Cell with a Rotating Cathode", Biosensors and Bioelectronics, vol. 22, pp. 3252-3255, 2007.

[39] A. R. Schoen, "Carbon Fiber Electrode as an Electron Acceptor for a Microbial Fuel Cell Using Geobacter", Cantaurus McPherson College Division of Science and Technology, vol. 15, pp. 24-26, 2007.

[40] M.-S. Kim and Y.-J. Lee, “Optimization of Culture Conditions And Electricity Generation Using Geobacter Sulfurreducens in a Dual-chambered Microbial Fuel-Cell", Bioenergy Research Center, Korea Institute of Energy Research, vol. 35, no. 23, pp. 1-7, 2009.

[41] J. S. Geelhoed, H. Hamelers and A. Stams, "Electricity-mediated Biological Hydrogen Production", Current Opinion in Microbiology, vol. 13, no. 3, pp. 307-315, 2010.

[42] D. Lowya, L. Tender, J. Zeikus, D. Park and D. Lovley, "Harvesting Energy from the Marine Sediment-Water Interface Kinetic Activity of Anode Materials", Biosensors and Bioelectronics, vol. 21, no. 11, pp. 2058-2063, 2006.

[43] B. Logan and J. Regan, "Electricity-producing Bacterial Communities in Microbial Fuel Cells", TRENDS in Biotechnology, vol. 14, no. 12, pp. 512-518, 2006.

[44] B. E. Logan, "Scaling up Microbial Fuel Cells and Other Bioelectrochemical Systems", Applied Microbiology Biotechnology, vol. 85. no. 6, pp. 1665-1671, 2010.
[45] Greenpeace Internacional. Revolución Energética 2010. [En línea] Disponible en: http://www.greenpeace.org/raw/content/ espana/reports/100607-03.pdf.

[46] Wikiciencia - ciencia tecnología colaborativa, tecnología. Generación de energía no convencional. [En línea] Disponible en: http://www.wikiciencia.org/tecnologia/ energia/no-convencional/index.php.

[47] Liceo Sololla C, Centro docente. [En línea] Disponible en: http://liceosorolla. es/images/alumnos/2ESOCURSO0607a/ Energias-renovables-02_03.pdf.

[48] Revista de Divulgación del I.E.S. Victoria Kent. Rincón de la ciencia. [En línea] Disponible en: http://centros5.pntic.mec. es/ies.victoria.kent/Rincon-C/Curiosid/Rc63/Rc-63b.htm.

[49] Organismo Internacional de Energía Atómica (IAEA). [En línea] Disponible en: http://www.iaea.org.

[50] Organización de las Naciones Unidas para la Educación, la Ciencia y la Cultura (UNESCO). Programa Mundial de Evaluación de Recursos Hídricos [En línea] Disponible en: http://www.unesco.org.

[51] Periódico El Espectador. [En línea] Disponible en: www.elespectador.com.

[52] Grupo de Estudios Económicos de Juan Carlos Ruiz, con el apoyo de ECONE estudio. [En línea] Disponible en: http:// estudioseconomicos.com.co/anexo/ temas/9bd_carbon_mundo_03_2011.pdf.

[53] Asociación Empresarial Eólica. Manuales de energías renovables 3, Energía eólica. [En línea] Disponible en: http://www.ener- 
giasrenovables.ciemat.es/adjuntos_documentos/Energia_Eolica.pdf.

[54] Un futuro con energías renovables. Minería y petróleo en Colombia. [En línea] Disponible en: http://www.paisminero.com.

[55] Las energías renovables del futuro. [En línea] Disponible en: http://www.almediam. org/PDF/Renovables.pdf.

[56] Periódico Pichilemunews. La energía eólica en el mundo ya equivale a 200 centrales nucleares. [En línea] Disponible en: http://pichilemunews.blogcindario. com/2011/02/03774-la-energia-eolica-enel-mundo-ya-equivale-a-200-centrales-nucleares.html.

[57] Colegio Oficial Asociación Ingenieros de Telecomunicaciones Andalucía Occidental y Central. Energía solar fotovoltaica, grupo de nuevas actividades profesionales. [En línea] Disponible en: http://www. coitaoc.org/files/estudios/energia_solar_ fotovoltaica_2e5c69a6.pdf.

[58] BUN -CA, Fundación Red de Energía. Manuales sobre energías renovables solar fotovoltaica. [En línea] Disponible en: http://www.bun-ca.org/publicaciones/FOTOVOLT.pdf.

[59] Almería Medio Ambiente, ALMEDIAM, El boletín independiente para la conservación y protección de la naturaleza almeriense". Las energías renovables son el futuro. [En línea] Disponible en: http://www.almediam.org/PDF/Renovables.pdf.

[60] Instituto Geológico y Minero de España, Ministerio de Ciencia e Innovación. Ma- nual de geotermia. [En línea] Disponible en: http://static.noticiasdenavarra.com/ docs/2010/11/30/manual-geotermia.pdf.

[61] Ecologia 1 bolg.com. Indonesia busca explotar la energía geotérmica de sus volcanes. [En línea] Disponible en: http://www. ecologiablog.com/categoria/geotermica.

[62] M. J. Wilkins, et ál, "Development of a Biomarker for Geobacter Activity and Strain Composition; Proteogenomic Analysis of the Citrate Synthase Protein During Bbioremediation of U(VI)", Applied Microbiology and Blackwell Publishing Ltd, vol. 4, no. 1, pp. 55-63, 2010.

[63] A. L. N'Guessan, et ál, "Molecular Analysis of Phosphate Limitation in Geobacteraceae During the Bioremediation of a Uranium-Contaminated Aquifer," International Society for Microbial Ecology, vol. 4, pp. 253-266, 2010.

[64] D. E. Holmes, et ál, "Subsurface Clade of Geobacteraceae that Predominates in a Diversity of Fe(III)-Reducing Subsurface Environments", International Society for Microbial Ecology, vol. 1, no. 8. pp. 663677, 2007.

[65] M. J. Wilkins, et ál., "Development of a Biomarker for Geobacter Activity and Strain Composition; Proteogenomic Analysis of the Citrate Synthase Protein During Bioremediation of U(VI)", Microbial Biotechnology, vol. 4, no. 1, pp. 55-63, 2011.

[66] D. R. Lovley, "Extracellular Electron Transfer: Wires, Capacitors, Iron Lungs, and More", Geobiology, vol. 6, no. 3, pp. 225-231, 2008. 